\title{
AsPeCTOS GENERALES EN TORNO A LA CLÁUSULA REBUS SIC STANTIBUS (TEORÍA DE LA IMPREVISIÓN), EN ESPAÑA
}

[General regarding the rebus sic stantibus clause (Theory of unpredictability) in Spain]

\author{
José MaXimiliano Rivera Restrepo* \\ Universidad Gabriela Mistral \\ Rodrigo BARCIA LEHMANN** \\ Universidad Finis Terrae
}

\begin{abstract}
RESUMEN
La cuestión de la revisión judicial de los contratos constituye una importante materia del Derecho civil. Dentro de ella se enmarca la llamada cláusula rebus sic stantibus, según la cual, toda vez que varíen las circunstancias existentes al momento de celebrar un contrato $y$, siempre que,
\end{abstract}

\begin{abstract}
The question of judicial review of contracts is an important matter of civil law. Within it called rebus sic stantibus clause falls, according to which, since the circumstances vary upon executing a contract, provided that such modification means a serious injury
\end{abstract}

RECiBido el 8 de marzo y APROBADO el 1 de diciembre de 2016

* José Maximiliano Rivera Restrepo, Abogado de la Universidad de Chile y Magíster en Derecho, con mención en Derecho Privado por la Universidad de Chile. Máster Universitario en Derecho Privado por la Universidad Complutense de Madrid. Doctor en Derecho Civil por la Universidad Complutense de Madrid. Profesor de Jornada de Derecho Civil en la Universidad Gabriela Mistral. Notario Público, Conservador de Bienes Raíces, Comercio, Minas y Archivero Judicial Suplente de Tocopilla. Dirección postal: Universidad Gabriela Mistral, Ricardo Lyon Nº 1177, Providencia, Santiago de Chile, Código Postal: 7510549. Correo electrónico: jose. rivera@ugm.cl

** Rodrigo Barcia Lehmann es Abogado; MBA Economía y Dirección Internacional de Empresas, MEDI, Universidad Autónoma de Madrid; European Master in Law and Economics, Complutense und Hamburg Universität; Doctor en Derecho Privado, Universidad Complutense de Madrid, 2002; Profesor Titular, Facultad de Derecho de la Universidad Finis Terrae. Dirección postal: Universidad Finis Terrae, Avenida Pedro de Valdivia No 1509, Providencia, Santiago de Chile, Código Postal: 7501015. Correo electrónico: rbarcia@uft.cl. 
dicha modificación signifique una grave lesión en los derechos de una de las partes, se podrá intervenir en el negocio jurídico, ajustándolo a las nuevas circunstancias existentes. En este ensayo, se aborda brevemente la cláusula rebus sic stantibus: su consagración, requisitos y su ámbito de aplicación en doctrina y legislación española. Particularmente, nos interesa analizar algunos aspectos de la Propuesta (española) de Anteproyecto de Ley de Modernización del Derecho de Obligaciones y Contratos (en adelante la Propuesta).

\section{Palabras ClaVe}

Cláusula rebus sic stantibus imprevisión - revisión judicial de los contratos - contrato. to the rights of one of the parties, may intervene in the legal business, adjusting to new circumstances prevailing. In this paper, we briefly address the rebus sic stantibus: His consecration, requirements and its scope in doctrine and Spanish legislation. We particularly interesting to analyze some aspects of the proposal (spanish) of Draft Law on Modernization of the Law on Obligations and Contracts (hereinafter the proposal).

\section{KEYWORDS}

Rebus sic stantibus clause unpredictability - judicial review of contracts - contract.

\section{INTRODUCCIÓN}

En el Derecho histórico, la cláusula rebus sic stantibus ${ }^{1}$, luego de largos periodos de ostracismo (generalmente debido a la bonanza económica) ${ }^{2}$, renace en periodos de crisis económica. Dado el contexto económico de España, hoy más que nunca se hace necesario determinar su verdadero ámbito de aplicación. En las líneas que siguen esperamos enunciar los aspectos generales de la cláusula rebus sic stantibus, así como la necesidad de contar con una norma general que la consagre. En este sentido, se

${ }^{1}$ Al respecto, vid.c Barcia Lehmann, Rodrigo, Breve Análisis de la Teoría de la Imprevisión en el Derecho Chileno, en Tribunal Supremo de Justicia (editor), Libro de Homenaje al Prof. J. L. Aguilar (Colección de Libros Homenaje, n 5, Caracas, 2002), I, pp. 191 a 211; Barcia Lehmann, Rodrigo, ¿Es Posible Construir la Teoría General del Contrato desde la Excepción: la Revisión Judicial del Contrato?, ahora, en Martinic, María Dora - Tapia R., M. (directores), Sesquicentenario del Código Civil de Andrés Bello: Pasado, Presente y Futuro de la Codificación (Santiago de Chile, Facultad de Derecho de la Universidad de Chile, LexisNexis, 2005), I,pp. 685 a 719.

${ }^{2}$ Esta cláusula ha tenido influencia en el Derecho Internacional Público en el que los tratados firmados por un Estado podían ser desconocidos en caso de revolución o de cambio de sistema de gobierno, como de monarquía a democracia. También fue opuesto entre diversos Estados Europeos para desconocer los tratados firmados en las guerras napoleónicas. Vid. De Castro y Bravo, Federico, El Negocio Jurídico (Civitas, Madrid, 1991), p. 315. 
establecerá la necesidad de regular la cláusula rebus sic stantibus, en el Código civil español, particularmente en su Libro IV, cuyo epígrafe es "De las obligaciones y contratos". Se enunciarán los ordenamientos jurídicos que aplican la cláusula rebus sic stantibus y se abordarán someramente sus presupuestos. A continuación, se analizará brevemente la cláusula rebus sic stantibus respecto de sus requisitos (I), su ámbito de aplicación (II), su consagración en el Derecho comparado (III), los problemas de aplicación que presenta una vez aceptada (IV), para luego detenernos en la Propuesta (V) y señalar algunas conclusiones (VI).

La consagración legislativa de esta cláusula significa dejar de lado la discusión en torno a una forma de entender el dogma de la intangibilidad de los contratos o principio de la fuerza obligatoria de los contratos, contenido en el artículo 1091 del Código civil español. En este sentido, se supera la discusión de la tensión entre los artículos 1091 y 1258 del Código civil español (entre nosotros entre los artículos 1545 y 1546 del CC chileno, respectivamente). La primera de las referidas normas, en ambos sistemas jurídicos, consagra el principio de la autonomía de la voluntad y la segunda tipifica el principio de la buena fe. La aplicación de la referida cláusula a través del principio de la buena fe en el Derecho español, presenta dos alternativas: (a) pensar que la cláusula rebus sic stantibus, cuyo principal fundamento sería la buena fe, constituye una excepción al artículo 1091 del Código civil, cláusula que presenta una aplicación restrictiva y excepcional,; y (b) que el principio de la buena fe tiene la función de moldear el contenido de las cláusula contractuales, determinado por la voluntad de los contratantes, ajustándola a la noción de justicia rebus sic stantibus

En definitiva, las diversas secciones del presente tabajo responden a las siguientes dos preguntas: ¿es necesaria la inclusión de la cláusula rebus sic stantibus a través de una modificación al Código civil?, o bien, ¿basta con el desarrollo jurisprudencial y doctrinal de la institución? Y, por último, superado el anterior debate surge una nueva interrogante: ¿Cuál es el alcance que se le debe otorgar a la cláusula rebus sic stantibus en el Derecho civil? 


\section{REQUisitos DE APLICACIÓN DE LA CLÁUSULA REBUS SIC}

STANTIBUS

\section{Que el cumplimiento de la obligación esté diferido en el tiempo ${ }^{3}$}

Si el nacimiento de la obligación es simultáneo con su cumplimiento, faltaría el periodo dentro del cual debe surgir el imprevisto, por lo tanto, esta teoría no opera tratándose de las obligaciones emergentes de los contratos de ejecución instantánea ${ }^{4}$. Dicho de otra manera, para que sea dable aplicar la cláusula rebus sic stantibus, la obligación debe emanar de un contrato de ejecución diferida o de un contrato de tracto sucesivo 5 .

${ }^{3}$ Los tribunales han establecido, en cuanto a los requisitos de aplicación de la cláusula rebus sic stantibus, lo siguiente: "Como señaló la Sentencia del Tribunal Supremo de fecha 15 de noviembre de 2000 (RJ/2000/9214), la existencia de «A.- Una alteración extraordinaria de las circunstancias en el momento de cumplir el contrato en relación con las concurrentes al tiempo de su celebración. B.- Una desproporción exorbitante, fuera de todo cálculo entre las prestaciones de las partes contratantes que aniquilen el equilibrio de las prestaciones. C.- Que todo acontezca por la sobreveniencia de circunstancias radicalmente imprevisibles"”. SAP DE NAVARRA de 20 de diciembre de 2002, (AC/2002/329). Vid. las sentencias del Tribunal Supremo, Sala de lo Civil, de 6 de junio de 1959 (RJ/1959/3026); de 23 de noviembre de 1962 (RJ/1962/5005); de 9 de mayo de 1983 (RJ/1983/2678); de 20 de abril de 1994 $(R J / 1994 / 3216)$, que añade que no tiene efectos retroactivos y de 27 de mayo de 2002 (RJ/2002/4573). Asimismo, vid. las sentencias de la Audiencia Provincial de A Coruña de 21 de octubre de 1994 (AC/1994/1829); de la Audiencia Provincial de Madrid, Sección 14, de 20 de febrero de 2001 (JUR/2001/184592); de la Audiencia Provincial de Asturias, Sección 5.a, de 4 de abril de 2001 (AC/2001/1046), que señala que sólo se aplica a los contratos a largo plazo de tracto sucesivo y ejecución diferida; de la Audiencia Provincial de Cádiz, Sección 2. a , de 10 de enero de 2012 (JUR/2012/77632) y de la Audiencia Provincial de Córdoba, Sección 1. a , de 14 de marzo de 2013 (JUR/2013/251585).

${ }^{4}$ Moisset De Españés Luis, La lesión en el nuevo artículo 954 del Código Civil argentino y en algunas legislaciones modernas, en Anuario de Derecho Civil 29 (1976), p. 1161.

5 En este sentido, la SAP DE BARCELONA de 16 de mayo de 2002, resolvió que: "En los contratos de tracto sucesivo o de larga duración, una alteración sobrevenida, no prevista, de las circunstancias tenidas en cuenta por las partes al contratar (piénsese que en el presente caso se prevé contractualmente una duración 5 años, pero se prolonga, a más de 25) puede, en determinados casos, producir la ruptura del equilibrio interno del contrato, convirtiendo en excesivamente onerosa la prestación de una de las partes, en cuyos supuestos entra en juego la cláusula rebus sic stantibus con la finalidad de remediar o restablecer el equilibrio o la economía interna del contrato (a cuya finalidad también se dirigen las teorías de la desaparición de la base del negocio, de la equivalencia de prestaciones o de la equidad, al amparo del artículo 3.2 CC)...". SAP DE BARCELONA de 16 de mayo de 2002, (JUR/2002/189101). 


\section{Debe existir un hecho imprevisible}

Es preciso distinguir entre el hecho imprevisible y el hecho imprevisto. El primero es aquel que las partes no pudieron razonablemente prever al tiempo de celebrar el contrato; el segundo, en cambio, es aquel que efectivamente las partes no previeron al momento de celebrar el negocio ${ }^{6}$. En otras palabras, el hecho imprevisible se determina in abstracto, comparando la conducta particular del contratante con el comportamiento que el Derecho le exige a un hombre medio (buen padre de familia o persona normal); en cambio, el hecho imprevisto se determina caso a caso, in concreto, analizando únicamente la conducta del contratante. Por lo dicho, estimamos que es preferible hablar de hecho imprevisible, como elemento o requisito de aplicación de la cláusula rebus sic stantibus. En este sentido, conforme al Diccionario de la Lengua Española, imprevisión consiste en la falta de previsión, y previsión es la "[...] acción de disponer lo conveniente para atender a contingencias o necesidades previsibles". Ambos vocablos provienen del verbo prever, que significa "[...] ver con anticipación, conocer, conjeturar por algunas señales o indicios lo que ha de suceder" . Con el fin de precisar la distinción entre lo imprevisto y lo imprevisible. Lo primero es todo aquello que no fue sido conocido o visto con anticipación por los contratantes, mientras que lo imprevisible es todo lo que no ha podido ser conocido con anterioridad, por una persona media, actuando en circunstancias normales. Es decir, estimamos que para determinar si un hecho es o no imprevisible, se debe atender a un criterio objetivo, comparando la actuación concreta de la parte, con la conducta que tendría una persona media en iguales circunstancias.

\section{Que este hecho, sin que haga imposible el cumplimiento, lo transforma} en notablemente más gravoso

Este requisito se explica, por cuanto si el hecho imprevisible hiciere imposible el cumplimiento de la obligación, estaríamos frente a la figura del caso fortuito o fuerza mayor ${ }^{8}$. Esto significa que para aplicar la cláusula

${ }^{6}$ En este sentido, García Caracuel, Manuel, La alteración sobrevenida de las circunstancias contractuales (Madrid, Dykinson, S. L., 2014), p. 272, expresa lo siguiente: "El origen de la alteración circunstancial debe ser totalmente ajeno a la voluntad de las partes; es más, debe quedar totalmente fuera de su esfera de control". Al respecto, vid. también Palacios Ramírez, Jaime, La incidencia de la crisis económica en la doctrina general de los contratos (Logroño, Servicio de Publicaciones, Universidad de La Rioja, 2014), p. 272.

7 Real Academia Española, Diccionario de la Lengua Española (Vigésima segunda edición, Madrid, Editorial Espasa-Calpe, S. A., 2001), II, p. 1831.

${ }^{8}$ En este sentido, la jurisprudencia exige que el hecho imprevisible transforme a la obligación de una de las partes en un deber notablemente más gravoso, es decir, 
rebus sic stantibus, no basta con que exista un acontecimiento imprevisible, sino que además, se exige que éste destruya el equilibrio conmutativo9 existente entre las prestaciones recíprocas en un grado superlativo ${ }^{10}$. Así lo ha entendido la doctrina, cuando exige que este hecho sea de tal intensidad en la ejecución de la obligación, que convierta a la prestación en excesivamente más gravosa, alterando el equilibrio del contrato ${ }^{11}$. Ello se determina conforme a teoría de la base del negocio y a la asignación o distribución

no cualquiera alteración de las circunstancias fácticas da lugar a la aplicación de la cláusula rebus sic stantibus, sino que dicha alteración debe ser esencial. En este punto, siguiendo a Lacruz Berdejo, José Luis - Sancho Rebullida, Francisco - Luna Serrano, Agustín; Delgado Echeverría, Jesús; Rivero Hernández, Francisco - Rams Albesa, Joaquín, Elementos de Derecho Civil (4a edición revisada y puesta al día por F. Rivero Hernández, Editorial Dykinson, Madrid, 2007), p. 511, los: “...presupuestos de aplicación de la facultad de modificar el contrato, según la jurisprudencia (SS. 27 de junio 1984, 23 abril 1991, 24 junio 1993, 4 febrero 1995, entre muchas otras), son éstos: $1^{\circ}$ Alteración extraordinaria de las circunstancias en el momento del cumplimiento del contrato en relación con las concurrentes al tiempo de su celebración. $2^{\circ}$ Desproporción exorbitante y fuera de todo cálculo entre las prestaciones de las partes contratantes que verdaderamente derrumba el contrato por aniquilamiento del equilibrio de tales prestaciones. $3^{\circ}$ Que todo acontezca por la sobrevenida aparición de circunstancias radicalmente imprevisibles. $4^{\circ}$ Que se carezca de otro medio para remediar y salvar el perjuicio". En este mismo sentido, STS de fecha $1^{\circ}$ de octubre de 2008, (RJ/2008/4601), SAP DE VALENCIA, de 6 de noviembre de 2000, (JUR/2001/47223); SAP DE BADAJOZ de 10 de junio de 2002 (JUR/2002/201574); $S A P$ DE CÁdiz de 18 de junio de 2004, (JUR/2004/258243); SAP DE CANTABria de 18 de mayo de 2006, (JUR/2006/177729); SAP DE BARCELONA de 25 de mayo de 2006, (JUR/2006/259574).

9 Berrocal Lanzarot, Ana Isabel, La cláusula rebus sic stantibus. A propósito de la Sentencia del Tribunal Supremo, del Pleno de la Sala Primera, de 17 de enero de 2013, en: García Collantes, José Manuel (director), Cuadernos de Derecho y Comercio 60 (Madrid, Consejo General de los Colegios Oficiales de Corredores de Comercio, 2014), p. 223.

${ }^{10}$ En este sentido, Sánchez Lorenzo, Sixto, Hardship en la contratación internacional: Principios comunes para una unificación desde el Derecho comparado, ahora en Vargas Gómez-Urrutia, Marina - Salinas de Frías, Ana (coordinadoras), Soberania del Estado y Derecho internacional (Homenaje al Profesor Juan Antonio Carrillo Salcedo) (Sevilla, Servicios de Publicaciones de las Universidades de Córdoba, Sevilla y Málaga, 2005), p. 1273, señala que: "La excesiva onerosidad o hardship, [...] constituye una situación diferente de los supuestos de imposibilidad o fuerza mayor, incluida la imposibilidad económica u onerosidad extrema, si bien la determinación de si la onerosidad es excesiva o extrema no deja de ser una cuestión puramente relativa".

${ }^{11}$ De Amunátegui Rodríguez, Cristina, La cláusula rebus sic stantibus (Valencia, Editorial Tirant lo Blanch, 2003), pp. 262-263. 
contractual de los riesgos ${ }^{12}$. La mayor onerosidad debe ser entendida con carácter objetivo, esto es, excluyendo las consideraciones de índole personal que tiene el deudor. Debe compararse la prestación existente al tiempo de celebrar el negocio, con la resultante del hecho imprevisible, de tal modo que, si el equilibrio resultante es sustancialmente diferente, entonces tiene lugar la cláusula rebus, todo ello conforme a la buena $\mathrm{fe}^{1314}$.

\section{II. ÁMBITO DE APLICACIÓN DE LA CLÁUSULA REBUS SIC STANTIBUS EN EL DERECHO ESPAÑOL}

En general, la doctrina ha planteado que el ámbito propio de la cláusula rebus sic stantibus ${ }^{15}$, es el de las obligaciones y contratos ${ }^{16}$. Sin embargo, la jurisprudencia ha extendido este ámbito, a relaciones jurídicas propias de otras materias, siempre que reúnan los requisitos analizados en el apartado anterior ${ }^{17}$. En el ámbito de los contratos, se exige que se trate de un contrato

12 Trigo Sierra, Eduardo y Pérez-Pujazón, María Encarnación, El nuevo tratamiento jurisprudencial de la doctrina de la cláusula rebus sic stantibus, en Actualidad Jurídica Uría Menéndez, 39 (2015), p. 93.

${ }^{13}$ García Caracuel, cit. (n. 6), p. 338.

${ }^{14}$ Se ha discutido si la cláusula en estudio debe aplicarse sólo en la medida que el hecho imprevisible afecte a una cierta categoría o clase de deudores. Ello implicaría que, en principio, la doctrina de la cláusula rebus sic stantibus no es aplicable cuando el hecho imprevisible lesione a uno o más deudores aislados, sino que se exige que el imprevisto afecte a una cierta categoría o clase de deudores. Esta exigencia se sustenta en razones de índole históricas, ya que la cláusula rebus sic stantibus nació para hacer frente a catástrofes económico-sociales, que afectaban a un importante segmento de la población de un estado (guerras, crisis económicas, etc.). Sin embargo, en honor a la verdad, la mayoría de los autores modernos no exigen este elemento para que el juez aplique la cláusula rebus sic stantibus, y creemos que ello se debe a que, como ya lo hemos señalado, en estos casos la esta cláusula pasa a ser el Derecho común. Por ejemplo, una revisión general de las condiciones de la contratación dada una crisis financiera es una regulación de la cláusula rebus sic stantibus, la que se transforma en el Derecho común dados los acontecimientos excepcionales que se regulan. El supuesto analizado en este trabajo es diferente por cuanto entiende a la referida cláusula dentro de la teoría general del contrato, o sea, la desvincula a situaciones de orden excepcional como es una guerra, crisis económica, catástrofe natural, etc.

${ }_{15} \mathrm{Al}$ respecto, vid. Marín Narros, Héctor Daniel, La aplicación de la cláusula rebus sic stantibus en los contratos bancarios y su interpretación por la STS de 29 de octubre de 2013 y la jurisprudencia menor, en Revista Critica de Derecho Inmobiliario 747 (2015), pp. 536 y ss.; Momberg URIBe, Rodrigo, Teoría de la imprevisión: la necesidad de su regulación legal en Chile, en Revista Chilena de Derecho 15 (2010), pp. 58-61.

${ }^{16}$ García Caracuel, cit. (n. 6), p. 341.

${ }_{17}$ En cuanto a la aplicación de la cláusula rebus sic stantibus, en materia laboral, 
de tracto sucesivo o de ejecución diferida, es decir, que exista un lapso en el cual pueda surgir el acontecimiento imprevisto y extraordinario, que imponga un esfuerzo adicional al deudor, fuera de todo cálculo. Lo anterior es lógico, por cuanto al extenderse la vida del contrato durante un tiempo prolongado, es posible que surjan hechos imprevistos que provoquen la ruptura del equilibrio de las prestaciones recíprocas. Ahora bien, en 2014, el TS dictó dos sentencias que STS de 30 de junio, (RJ/2014/333) y STS de 15 de octubre, $(R J / 2014 / 591)$, que, en opinión de Trigo Sierra y Pérez-Pujazón, suponen un cambio de criterio jurisprudencial, despojando a la cláusula rebus, del carácter restrictivo y excepcional ${ }^{18}$. La $S T S$ de 30 de junio de 2014, (RJ/2014/ 333), dispone que: "Respecto de la cuestión de fondo que plantea el presente caso, en torno a la valoración del régimen de aplicación de la cláusula rebus sic stantibus, debe señalarse que en la actualidad se ha producido un cambio progresivo de la concepción tradicional de la figura referenciada en un marco de aplicación sumamente restrictivo o excepcional, como corresponde a una cláusula "peligrosa» y de admisión "cautelosa», con fundamento derivado del criterio subjetivo de la equidad y con una formulación rígida de sus requisitos de aplicación: «alteración extraordinaria», "desproporción desorbitante» y circunstancias «radicalmente imprevisibles»; caso de la sentencia de esta Sala, de 10 de febrero de 1997, que es tomada como referente por la Audiencia Provincial" ${ }^{19}$. Por su parte, la STS de 15 de octubre de 2014, (RJ/2014/591), cuyo ponente es Francisco Javier ORDUÑA MORENO, dispone que: "[...] 3.1 Que, por aplicación de la doctrina jurisprudencial relativa a la cláusula rebus sic stantibus, procede la modificación del contrato, de 25 de febrero de 1999, respecto de la relación arrendaticia del Hotel Ibis, en el sentido de reducir la renta anual un $29 \%$ respecto de la renta vigente en el momento de interposición de la demanda [...]". Así, "[L]a Sala [Primera Civil del TS] pasó a admitir que la crisis económica podía constituir una alteración extraordinaria e imprevisible de las circunstancias que permitiría acudir a esta regla especialmente a particulares que actuaran en calidad de tales [... ${ }^{202}$. Izquierdo Tolsada, comentando esta STS, se pregunta acerca del

vid. Castro Conte, Macarena, El sistema normativo del salario: ley, convenio colectivo, contrato de trabajo y poder del empresario (Madrid, Dykinson, 2007), pp. 469 y ss.

18 Trigo Sierra, E. y Pérez-Pujazón, cit. (n. 12), p. 88.

19 En este sentido, se pronuncia igualmente la STS de 17 de enero de 2013. Martínez Atienza, Gorgonio, Jurisprudencia civil, en Derecho civil, penal sustantivo y procesal. Jurisprudencia del Tribunal Supremo (2015), p. 349.

${ }^{20}$ Con relación a esta STS, vid. Luna Yerga, Álvaro - Xiol Bardají, María, Rebus sic stantibus: ¿Un paso atrás? Comentario a la STS, 1a, 15.10.2014 (Ar. 6129) y a 
verdadero alcance de la cláusula rebus ${ }^{21}$, y señala que: "A mi entender, la doctrina de la cláusula r.s.s., tal y como se había entendido hasta hace poco, no dejaba de estar "plenamente normalizada» ni dejaba de ser «claramente compatible con el sistema codificado" 22 . Por su parte, la STS de 24 de febrero de 2015, (RJ/2015/64), dispone que: "Planteada la cuestión de fondo en torno a la aplicación de la cláusula rebus sic stantibus debe señalarse que, recientemente, esta Sala ha profundizado en la moderna configuración que presenta esta figura en la actualidad delimitando la doctrina jurisprudencial aplicable en las sentencias de 30 de junio de 2014, núm. 333/2014 y 15 de octubre de 2014, núm. 591/2014. En esta línea, y dentro del necesario ajuste o adaptación de las instituciones o figuras jurídicas a la realidad social del momento, así como al desenvolvimiento doctrinal consustancial al ámbito jurídico, las citadas sentencias ya establecen una configuración plenamente normalizada de la cláusula rebus sic stantibus, en donde su prudente aplicación deriva de la exigencia de su específico y diferenciado fundamento técnico y de su concreción funcional en el marco de la eficacia causal del contrato". En contra se pronuncia Sánchez Peí Valle, quien señala que: "[O]pera la cláusula rebus sic stantibus, que si no está plasmada en vivas y categóricas normas en nuestro derecho positivo, la alentadora jurisprudencia del Tribunal Supremo permite ya configurar en su aplicación”23. Naturalmente, se podría justificar la aplicación de esta teoría a los contratos unilaterales y bilaterales, que no sean de tracto sucesivo $^{24}$. Así, puede ser que una de las partes de un contrato unilateral

la jurisprudencia posterior de la Sala Primera del Tribunal Supremo sobre la regla rebus sic stantibus, en InDret. Revista para el Análisis del Derecho 2 (2015), p. 8.

${ }^{21}$ En México, también algunos autores cuestionan el verdadero alcance de la cláusula rebus, así, para López MONROY, José de Jesús, La cláusula rebus sic stantibus o teoría de la imprevisión, en PatiÑo ManfFer, Ruperto, Cultura Jurídica. De los Seminarios de la Facultad de Derecho 3 (2011), p. 78, "[D]e ninguna manera resolverían el fondo del asunto".

${ }^{22}$ IZQUIERdo TolsAda, Mariano, La cláusula rebus sic stantibus no puede dar tanto de sí, en Boletín Mercantil 18 (2014), www.vlex.com

${ }^{23}$ Sánchez Peí Valle, José, Sugerencias a la doctrina de la cláusula rebus sic stantibus, en Revista Crítica de Derecho Inmobiliario 311 (1954), p. 264.

${ }^{24}$ Si se admite que procede la revisión judicial de un contrato unilateral, se debe determinar con qué parámetro se debe comparar la prestación que se ha hecho exorbitante. A diferencia de lo que acontece en un contrato bilateral, el desequilibrio exorbitante no se puede apreciar comparando la prestación que se ha hecho excesiva con la inexistente prestación correlativa. Por lo que, para apreciar la desproporción, se debe comparar el cumplimiento pendiente con la obligación originariamente contraída. Vid. Melich Orsini, José, La revisión judicial del contrato por onerosidad excesiva, en Revista de Derecho de la Universidad Católica de Valparaiso XX (1999), p. 180. 
puede verse afectado por la teoría de la imprevisión. Un donante puede deber una suma menor en moneda extranjera al donatario y producto de una fuerte e imprevisible devaluación su obligación puede transformarse en excesivamente onerosa ${ }^{25}$.

Otra cuestión relevante que surge en relación a la aplicación de cláusula rebus sic stantibus, en materia contractual, consiste en determinar si ella se aplica o no a los contratos aleatorios ${ }^{26}$. Con respecto a esta cuestión, se ha dicho que en los contratos aleatorios, el riesgo constituye un elemento esencial del mismo, erigiéndose como la causa del contrato. Al tiempo de suscribir un contrato aleatorio, las partes no se encuentran en condiciones de determinar cuál será -en definitiva- el real valor de la prestación a que se obligan, ésta consiste, precisamente, en una contingencia incierta de ganancia o pérdida ${ }^{27}$. En este sentido, De Amunátegui señala que: "La aleatoriedad podrá provenir de que el tipo contractual en sí mismo lo sea (por ejemplo un contrato de seguro, una renta vitalicia), o de que las partes hayan configurado como aleatorio un contrato que no lo es en principio (por ejemplo la venta de cosa futura). Planteando la cuestión en sus términos adecuados, no se trata de excluir la posible aplicación de la cláusula a los contratos aleatorios como tales, sino de analizar si las circunstancias sobrevenidas afectan a lo podríamos llamar el núcleo propio de aleatoriedad de ese contrato. Si es así, el contrato deberá cumplirse a tenor de lo pactado sin posibilidad alguna de revisión; pero si lo acontecido afecta a otros aspectos de la obligación no expuestos al riesgo propio del contrato, sí podría ser de aplicación la cláusula. No habría, por tanto, que confundir lo que es el riesgo previsible con el imprevisible"28. En los contratos aleatorios habría un riesgo que las partes pudieron conocer, y eso es precisamente lo que tendría que determinar el juez. Para ello, la doctrina comparada, ha señalado que se distinguen dos tipos de aleas, el

${ }^{25}$ A este respecto existen las más variadas posiciones. En algunos ordenamientos jurídicos esta teoría se aplica a todo contrato, en otros en cambio sólo a los contratos a los contratos bilaterales. Y finalmente, en algunos países procede únicamente respecto de los contratos de ejecución diferida. En la primera situación están los Códigos civiles de Portugal (artículo 437) y de Cuba (artículo 20); en la segunda el de Guatemala (artículo 154) y en la tercera los de Bolivia (artículo 581), Perú (artículo 1440) y la mayoría de los Códigos civiles latinoamericanos. Vid. Melich Orsini, cit. (n. 24), pp. 175 y 176.

${ }^{26}$ No en todos los ordenamientos jurídicos se acepta esta posibilidad. El ex - artículo 1198 del C.C. argentino la admite expresamente. A favor de ella está, en Francia, Ghestin, Jacques, Traité de Droit Civil: Les Obligations. Les Effets du Contract (Paris, Librairie Générale de Droit et Jurisprudence, 1992), p. 291.

${ }^{27}$ De Amunátegui Rodríguez, cit. (n. 11), p. 259.

${ }^{28}$ De Amunátegui Rodríguez, cit. (n. 11), pp. 240-241. 
alea normal, que equivale a la incertidumbre económica que experimenta todo contratante al celebrar el negocio y, el alea jurídica, que consiste en aquella incertidumbre que forma parte de la relación contractual. La doctrina señala que el alea jurídico es la que tipifica al contrato aleatorio, pues, si aceptamos la primera, por definición todos los contratos serían aleatorios. Ahora bien, en esta clase de contratos, más que hablar de prestaciones, habría que utilizar la denominación posibilidad de obtener una ganancia, por ello será relevante establecer si las partes han asumido o no un riesgo fuera de todo pronóstico, al celebrar el contrato aleatorio, para proceder a aplicar la cláusula rebus sic stantibus ${ }^{29}$. En este sentido podemos agregar que el alea, siendo un elemento de la esencia de todo contrato aleatorio, podría estar desvinculado de la prestación que sufre la imprevisión. En dicho caso cabría la aplicación de la cláusula. Como si se compra un yacimiento de minero -que podría estimarse como aleatorio con relación a la tecnología existente para extraer el mineral-, que se debe pagar a plazo en dólares en equivalente en pesos, y por un hecho imprevisible se devalúa el peso en un $1.000 \%$, en dicho caso entendemos que procedería la aplicación de la referida cláusula.

Por último, se debe indicar que la jurisprudencia española ha extendido el ámbito de aplicación de la cláusula rebus sic stantibus, a otras instituciones, fuera del Derecho de los contratos. Dicha cláusula serviría de argumento para justificar una determinada solución. Así, el Tribunal Supremo se ha referido a ella en materia de pensión de alimentos ${ }^{30}$, en la STS de 14 de febrero de 1976, (RJ/1976/617); cláusula penal ${ }^{31}$ y en materia de Derecho urbanístico ${ }^{32}$. Sin embargo, la aplicación de esta cláusula

29 También es interesante la discusión que se genera respecto de la aplicación de esta cláusula a los contratos de opción. LeONSEGUi Guillot, Rosa Adela, El contrato de opción como contrato atípico de tracto único: examen jurisprudencial de la aplicabilidad de la resolución por cambio o alteración de las circunstancias, en Revista de Derecho UNED 10 (2012), p. 342, se refiere a la improbable aplicación de la cláusula rebus sic stantibus a los contratos de opción. En el mismo sentido se pronuncia MARTíNez Velencoso, Luz, Riesgo negocial v. "cláusula rebus sic statibus». Comentario a las SSTS, 1a, 1.6.2010 y 21.7.2010, en InDret. Revista para el Análisis del Derecho 10, Barcelona, 2011, pp. 5-6.

${ }^{30}$ Berrocal Lanzarot, cit. (n. 9), pp. 620-644.

31 JiméNEz MuÑoz, Francisco Javier, La moderación judicial de la cláusula penal, en Revista Crítica de Derecho Inmobiliario 653 (1999), p. 1485.

32 De la Iglesia Prados, Eduardo, Consecuencias contractuales derivadas del incumplimiento urbanistico, ahora en Morillas Cueva, Lorenzo (director), SuÁrez LóPEZ, José María (coordinador), Urbanismo y corrupción política. (Una visión penal, civil y administrativa) (Madrid, Dykinson, S. L., 2013), p. 687. 
a cualquier obligación civil ${ }^{33}$, nos parece excesivo. Ello se debe a que la cláusula en estudio aminora los rigores del pacta sunt servanda ${ }^{34}$, y la corrección de obligaciones no contractuales se deba hacer conforme a otros criterios, como el pago de lo no debido, el enriquecimiento injusto, etc.

\section{CONSAGRACIÓN DE LA CLÁUSULA REBUS SIC STANTIBUS EN}

\section{el Derecho comparado}

En los Estados Unidos se acoge la teoría de la imprevisión, mediante el cambio de circunstancias (changed circumstances), que contempla casos de imposibilidad de cumplimiento, la impracticabilidad comercial y frustración del contrato ${ }^{35}$. El artículo 2, sección 615 del "Uniform Commercial

33 A favor de esta posición se pronuncia Parada Guzmán, César, Fundamentos de la Teoría de la Imprevisión (Santiago de Chile, Colegio de Abogados de Chile, 1994), p. 7; en cambio otros autores, como PeñaIlillo Arévalo, Daniel, La revisión judicial de obligaciones y contratos, en Revista de Derecho, Universidad de Concepción LXVIII (2000), pp. 230 y 231, se inclinan por su aplicación general.

${ }^{34}$ En este contexto, Castiñeira Jerez, Jorge, Pacta sunt servanda, imprevisión contractual y alteración sobrevenida de las circunstancias, en Revista Aranzadi de Derecho Patrimonial 29 (2012), p. 73, afirma que: "[...] el principio pacta sunt servanda tiene una doble vertiente: una positiva y otra negativa. La positiva consiste en que las partes contratantes se obligan a todo aquello expresamente pactado, así como a cualesquiera otras consecuencias derivadas de las fuentes de interpretación e integración previstas por el ordenamiento (artículo 1258 del Código Civil). La vertiente negativa, por el contrario, se caracteriza por la irrelevancia de cualesquiera otros elementos o circunstancias no contempladas o no deducibles, a través de una interpretación o de la integración (cuando ésta debe tener lugar), del contrato".

${ }^{35}$ La doctrina comparada utiliza diferentes expresiones para referirse a esta teoría. Tal vez una de las expresiones más recurrente es la denominación de origen francés ("théorie de l'imprévision"). En este sentido, Flour, Jacques - AUBERT, JeanLuc - Savaux, Éric, Droit Civil. Les obligations (París, Éditorial Dalloz, 2004), 1, pp. 310 y 312, expresan lo siguiente: "Dès 1916, et par l' arrêt Gaz de Bordeaux, non moins célèbre que celui qu'avait rendu la Cour de cassation dans l'affaire du canal de Crapone, le Conseil d'État a, au contraire, consacré la théorie de l'imprévisions. Une hausse du charbon -don't le Conseil constate que, déjouant toutes les prévisions, elle dépassait les limites extrêmes qui auraient pu être envisagées- avait «bouleversé l'économie» du contrat de concession. Un droit à indemnité a été reconnu à la compagnie concessionnarie contre l'autorité concédante, en raison des circonstances extracontractuelles -c'est-à-dire, au fond, des circonstances imprévues- où la première se trouvait ainsi placée". Esta expresión, sin embargo, no ha sido acogida en España en que la mayoría de la doctrina española utiliza la expresión cláusula rebus sic stantibus. Al respecto, De Castro Y Bravo, cit. (n. 2), p. 314; Állvarez CapeROCHIPI, José Antonio, Curso de Derecho de obligaciones. El Derecho de los contratos (Madrid, Civitas, 2002), pp. 107 y ss.; De Amunátegui Rodríguez, C., cit. (n. 11), pp. 15 y ss. y en esp. el título de la obra; De Cuevillas Matozzi, Ignacio - De 
Code" (UCC) de los Estados Unidos establece: “...si su ejecución de la manera pactada sería impracticable por la ocurrencia de una contingencia cuya no ocurrencia fue un presupuesto básico sobre el cual se celebró el contrato o por el cumplimiento de buena fe de cualquiera regulación gubernamental extranjera o doméstica aplicable u orden se pruebe o no posteriormente que ésta fue invalidada" (traducción de los autores). Y este supuesto ya se consagraba en el $\$ 265$ de la "Restatement of Contracts" (Compilación de los Contratos) de $1975^{36}$. En virtud de dicha norma se limitan los casos de frustración a las situaciones en las cuales por razón de circunstancias imprevistas, el cumplimiento se convierte en algo carente de valor, como sucede con alguna medida administrativa o una perturbación social grave que afecta el cumplimiento del contrato. No se debe confundir este supuesto con los casos de impossibility o de commercial impracticability en

Castro García, Jaime - González García-Mier, Rocío, Instituciones de Derecho civil patrimonial (4o edición, Madrid, Editorial Tecnos, 2011), pp. 232 y ss.; LACRUZ BERDEJO et al. cit. (n. 8), p. 507. En Estados Unidos a esta figura se le conoce como frustración del propósito ( doctrine of frustation of purpose» del contrato): KESSLER, Friedrich - Gilmore, Grant and Kronman, Anthony, Contracts. Cases and Materials ( $3^{a}$ edición, Aspen, Aspen law \& Business - Aspen Publishers, Inc., 1987), p. 862 y pp. 896 y 897; Murphy, Edward - Speidel, Richard - Ayres, Ian, Studies in Contract Law (Westbury, University Casebooks Series, New York, The Foundation Press, Inc., 1997), p. 713; Farnsworth, Allan, Contracts ( $3^{\text {a }}$ edición, Aspen, Aspen Law \& Business - Aspen Publishers, Inc., 1999), pp. 653-654.

${ }^{36}$ Como señala Chamie, José Félix, Frustration of Contract $e$ Impossibility of performance en el Common Law estadounidense, en: Revista de Derecho Privado, 18 (2010), p. 97, no se debe olvidar que los Restatments son una recolección de jurisprudencia no oficial elaborada por los Colegios de Abogados americanos, a diferencia del $U C C$ que es un instrumento oficial. En este sentido, la Corte Suprema de Washington estimó que la frustración del contrato debe darse respecto de las expectativas de ambas partes fijadas al tiempo de su celebración, que se verían frustradas por un hecho posterior al contrato, no imputable a las partes, y que afecta aspectos sustanciales del contrato (Felt v. McCarthy, 922 P. 2d 90 (Wash. 1996). En dicho caso la Corte resolvió que: "The rule stated in this Section sets out the requirements for the discharge of that party's duty. First, the purpose that is frustrated must have been a principal purpose of that party in making the contract. It is not enough that he had in mind some specific object without which he would not have made the contract. The object must be so completely the basis of the contract that, as both parties understand, without it the transaction would make little sense. Second, the frustration must be substantial. It is not enough that the transaction has become less profitable for the affected party or even that he will sustain a loss. The frustration must be so severe that it is not fairly to be regarded as within the risks that he assumed under the contract." Vid. http://law.justia.com/cases/washington/ supreme-court/1996/63317-7-1.html. 
los cuales el cumplimento, por regla general, es imposible ${ }^{37}$. Sin perjuicio de los casos precedentes, la jurisprudencia inglesa acepta la teoría de la imprevisión sólo en la medida que las partes la estipulen expresamente ${ }^{38}$. En el Derecho inglés, la teoría de la imprevisión se aplica a través de la doctrina de la frustración de los contratos o del término implícito, que se desarrolló a raíz de los casos, Krell v. Henry, Taylor v. Caldwell, Robinson v. Davidson y otros en materia de coronación ${ }^{39}$. La doctrina del Reino Unido tiene cierta similitud con la doctrina alemana de la base del negocio, ya que el juez debe de preguntarse ¿a qué acuerdo habrían llegado racionalmente las partes si, a la celebración del contrato, hubieran calculado el imprevisto? Así, Lord Sumner, en Hirji v. Cheong Yue S. S. Co., resuelve que "la frustración [...] se explica en la teoría como una

${ }^{37}$ En este sentido, WeISKopf, Nicholas, Frustration of Contractual Purpose - Doctrine or Myth?, en: St. John's Law Review, 70 (1996), p. 240, señala que: "See Restatement (second) of Contracts $₫ 265 \mathrm{cmt}$. a (1979). As explained in the comment, '[t] his Section deals with the problem that arises when a change in circumstances makes one party's performance virtually worthless to the other, frustrating his purpose in making the contract. It is distinct from the problem of impracticability ... because there is no impediment to performance by either party". Sin perjuicio de lo cual, también hay autores que sostienen que la impossibility o la commercial impracticability operan cuando los costos del cumplimiento para el deudor o vendedor, se hacen excesivos. Así, EISENBerg, Melvin, Impossibility, Impractiability, and Frustration, en: Berkeley Law Scholarship Repository (2009), pp. 210-211, es de la opinión que: "The terms impossibility and impracticability will be used primarily to refer to cases in which a seller is adversely affected by the occurrence of an unexpected circumstance because that occurrence either makes her performance impossible or significantly increases her cost of performance".

${ }^{38}$ El Reino Unido ha sido más renuente a aplicar la teoría de la imprevisión que Estados Unidos. De este modo Chamie, cit. (n. 36), p. 98, señala que: "Por ello, mientras en el common law inglés las cortes no se cansan de señalar que no tienen el poder de modificar el contrato (dando así soluciones que no llegan a ser equitativas a causa del binomio cumplimiento o resolución), en caso de eventos sobrevenidos que alteren el equilibrio de la operación, en el common law estadounidense, caracterizado por la atenuación del mencionado principio, tiene gran relevancia la constante búsqueda por parte del juez (como rule maker) de mecanismos que le permitan llegar a soluciones más equitativas para una apropiada distribución del riesgo derivado de eventos sobrevenidos no imputables a los contratantes".

39 Este caso fue, sin duda, fundamental. Como destaca Farnsworth, cit. (n. 35), p. 652, el año 1902 cuando el Rey Eduardo VII sucedió a la reina Victoria, Henry arrendó a Krell's House una suite para los días 26 y 27 de junio en la friolera de $£ 75$, dando un avance de $£ 25$ para ver la ceremonia desde su ventana; pero en definitiva una operación de apendicitis de Eduardo impidió la coronación. Ante ello Henry se negó a pagar las $£ 50$, por lo que Krell lo demandó de cumplimiento. 
condición o término del contrato, implícita ab initio por la ley..." ${ }^{40}$. Por otra parte, del análisis de la consideration en el common law se desprende que el juez no entra a analizar la magnitud del intercambio entre partes, sino simplemente si lo hubo ${ }^{41}$.

Naturalmente, el Derecho que desarrollaría de forma más detallada esta cláusula sería el Derecho alemán, que tempranamente aplico la teoría de la revisión judicial del contrato ${ }^{42}$. Esta tendencia se manifiestó en la interpretación que se realizó del $\mathbb{S} 242$ del $B G B$, que regula la buena fe, conforme a las tesis objetivas del contrato ${ }^{43}$. En el Derecho alemán, sólo una vez que el juez determina la extensión de la voluntad de las partes del negocio jurídico puede recurrir al análisis del evento imprevisto propio de la teoría de la imprevisión. El $\$ 242$ del $B G B$ no autoriza al juez a actuar en forma discrecional, sino conforme a una concepción objetiva de las relaciones contractuales. Conforme a Larenz, esta significación objetiva del contenido del contrato se manifiesta desde dos perspectivas. En primer lugar, como una limitación a la ampliación del deber de prestación, más allá del contexto del contrato o de la ley, y en segundo lugar, como fuente de un ulterior deber de conducta. $\mathrm{Y}$ en este sentido la doctrina alemana desarrollaría la teoría de la revisión judicial del contrato basada

${ }^{40}$ Kötz, Hein y Zweigert, Konrad, Introduction to Comparative Law (New York, Editorial Oxford University Press, 1998), pp. 559 a 561.

${ }^{41}$ En este sentido, los actos que carecen de consideration no son contratos porque ellos exigen un intercambio. Es especialmente interesante el caso en virtud del cual un constructor, contratado para edificar una obra, descubre que bajo el terreno que se debe levantar el edificio existe un pantano. Como dicho inconveniente afectaba los costos del proyecto, el dueño convino en pagarle al constructor una suma adicional. El dueño, a pesar de estar de acuerdo con la modificación del contrato, alegó que no era ejecutable por carecer de consideration. En este supuesto, a pesar de la oposición del propietario, la Corte mantuvo el acuerdo de modificación de contrato por considerar que no carecía de consideration.

${ }^{42}$ El Derecho alemán desarrolló una rica doctrina y jurisprudencia en torno a las formas de imposibilidad de las obligaciones (imposibilidad de cumplimiento; imposibilidad práctica e imposibilidad económica; imposibilidad subjetiva (imposibilidad fáctica e imposibilidad ética); e imposibilidad moral. Vid. García CARACuel, cit. (n. 20), pp. $244-250$.

${ }_{43}$ En los países germánicos, el Codex Maximilianeus Bavaricus Civilis de 1756, consagró expresamente la cláusula rebus sic stantibus, que fue incorporada también al Allgemeines Landrecht $(A L R)$ prusiano de 1774 y al Allgemeines Bürgerliches Gesetzbuch $(A B G B)$ austríaco de 1815. Sin embargo, esta cláusula fue rechazada en el $B G B$, que en esta materia se inspiró en el Code civil. Este fue el criterio de la Corte Suprema alemana, que sólo a raíz de la crisis de 1918 comienza a aceptar la teoría de la revisión judicial del contrato, por la interpretación que se ha sostenido de los $\$ S S$ $112,157,242,275$ y 306 del $B G B$. 
en la imposibilidad de ejecución. Así, la revisión judicial del contrato en principio, en el Derecho alemán, se aplicó a través de la imposibilidad económica de cumplimiento (wirtschaftliche Unmöglickeit) a raíz del ex $\$$ 275 del $B G B$. A este párrafo se le introdujeron importantes modificaciones por la Ley de Modernización del Derecho de las Obligaciones (Schuldrechtsmodernisierungsgesetz), que comenzó a regir el 1 de enero del 2002. Así se modificaron los $\$ \$ 275,280,284,286,311$ y 313, entre otros ${ }^{44}$.

En Italia, la revisión judicial del contrato está regulada expresamente, como excesiva onerosidad sobreviviente, en los artículos 1467 a 1469 del Codice civile $^{45}$.

En el ámbito Latinoamericano consagran expresamente la teoría de la imprevisión en Latinoamérica los códigos civiles de Guatemala (artículo 1330), Argentina (ex artículo 1198), Bolivia (artículos 581 a 583), Paraguay (artículo 672), y Perú (artículos 1440 a 1446). Asimismo, el Código

${ }^{44}$ El $₫ 313$ del $B G B$, a este respecto, es especialmente relevante. La referida norma establece que: " $\$ 313$ [Störung der Geschäftsgrundlage]. [1] Haben sich Umstände, die zur Grundlage des Vertrags geworden sind, nach Vertragsschluss schwerwiegend verändert und hätten die Parteien den Vertrag nicht oder mit anderem Inhalt geschlossen, wenn sie diese Veränderung vorausgesehen hätten, so kann Anpassung des Vertrags verlangt werden, soweit einem Teil unter Berücksichtigung aller Umstände des Einzelfalls, insbesondere der vertraglichen oder gesetzlichen Risikoverteilung, das Festhalten am unveränderten Vertrag nicht zugemutet werden kann. [2] Einer Veränderung der Umstände steht es gleich, wenn wesentliche Vorstellungen, die zur Grundlage des Vertrags geworden sind, sich als falsch herausstellen. [3] Ist eine Anpassung des Vertrags nicht möglich oder einem Teil nicht zumutbar, so kann der benachteiligte Teil vom Vertrag zurücktreten. An die Stelle des Rücktrittsrechts tritt für Dauerschuldverhältnisse das Recht zur Kündigung”. Trad.: $\$ 313$ [Cambio sustancial de las bases del contrato]. [1] Cuando las circunstancias bajo las cuales se celebró materialmente el contrato cambian de forma posterior a su conclusión y si las partes podrian no haber concluido el contrato o podrían haberlo concluido en términos diferentes, si ellos hubiesen podido prever el cambio de circunstancias, la adaptación del contrato podrá ser invocado en la medida en que, teniendo en cuenta todas las circunstancias del caso concreto, considerando en particular la asignación contractual o legal de los riesgos, no se puede esperarse de forma razonable que una parte siga siendo obligada por el contrato de la forma establecida. [2] Si las circunstancias materiales sobre las que se celebra la base del contrato posteriormente resultan ser incorrectas, son tratados de la misma manera que un cambio en las circunstancias. [3] Si la adaptación del contrato no es posible o no puede razonablemente ser impuesta a una de las partes, la parte en desventaja podrá resolver el contrato. En el caso de un contrato de tracto sucesivo, el derecho a la resolución se sustituye por el derecho al término de las obligaciones (traducción de los autores).

45 En Italia se comienza a aceptar esta teoría, en virtud de la interpretación que se hizo del artículo 1224 del Codice civile de 1865. En consideración a dicha norma, el deudor debe ejecutar las obligaciones con la diligencia de un buen padre de familia. Ello, sin perjuicio de su consagración definitiva en el Codice civile de 1942. 
de la Defensa del Consumidor brasileño (Ley 8.078 de 11 de septiembre de 1990) y el Código civil del Distrito y Territorio de México se refieren expresamente a la teoría de la imprevisión. El nuevo Código Civil y Comercial argentino -que ya había incorporado la teoría de la imprevisión a su legislación en el ex -artículo 1198, que pasaría a ser regulado en el nuevo artículo 1091- recoge la teoría de la frustración del propósito del contrato en su nuevo artículo $1090^{46}$. Además, su doctrina, sin desconocer la relación entre las teorías de la frustración del propósito del contrato e imprevisión, las diferencia claramente. Así, Caramelo señala que: "[E]n la frustración desaparece el móvil, la razón del contrato y esa es el motivo por el que la norma no habilita la revisión para restablecer el equilibrio, como sí ocurre en los supuestos de excesiva onerosidad sobreviniente. Lo que se verifica en este caso es la imposibilidad absoluta de alcanzar la finalidad buscada, aun cuando pueda ejecutarse la prestación” ${ }^{\prime 4}$.

Finalmente, a pesar de no ser Derecho comparado, es relevante el tratamiento que el denominado soft law ha hecho de esta figura. Las reglas de la UNIDROIT, el Anteproyecto de Código Europeo de Contratos, los Principios de Derecho Europeo de Contratos de la Comisión Lando (conocidos por sus siglas PECL), y, finalmente, los DCFR se refieren a la imprevisión. La Sección 2 de los Principios para los Contratos Comerciales

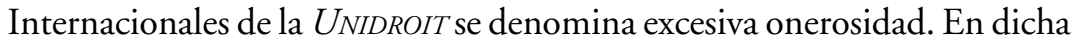
sección se define la referida expresión, en el artículo 6.2.2, haciéndola sinónimo de hardship, como excesiva onerosidad por alteración del equilibrio del contrato. Otro tanto sucede en el artículo 97.1 ${ }^{\circ}$ del Anteproyecto de Código Europeo de Contratos, presentado por Gandolfi. Los Principios de Derecho Europeo de Contratos de la Comisión de Lando no se refieren de forma tan clara a la teoría de la imprevisión, sin perjuicio que ella

${ }^{46}$ De esta forma la referida norma establece que: "Frustración de la finalidad. La frustración definitiva de la finalidad del contrato autoriza a la parte perjudicada a declarar su resolución, si tiene su causa en una alteración de carácter extraordinario de las circunstancias existentes al tiempo de su celebración, ajena a las partes y que supera el riesgo asumido por la que es afectada. La resolución es operativa cuando esta parte comunica su declaración extintiva a la otra. Si la frustración de la finalidad es temporaria, hay derecho a resolución sólo si se impide el cumplimiento oportuno de una obligación cuyo tiempo de ejecución es esencial'. Vid. http://www.infojus.gob.ar/docs-f/codigocomentado/CCyC_TOMO_3_FINAL_completo_digital.pdf

${ }^{47}$ Caramelo, Gustavo, Titulo II, Capitulo 13 - Extinción, modificación y adecuación del contrato, ahora en Herrera, Marisa - Caramelo, Gustavo - Picasso, Sebastián (directores), Álvarez, J. (dirección editorial), Código Civil y Comercial de la Nación Comentado, Libro Tercero, artículos 724 a 1250. Disponible en http:// www.infojus.gob.ar/docs-f/codigo-comentado/CCyC TOMO 3 FINAL completo digital.pdf 
se puede desprender de lo preceptuado en los artículos 1:201, 6:102 $2^{48}$, especialmente, del 6:111 ${ }^{49}$. Finalmente, el artículo III.-1:110 de los DCFR se refiere a la imprevisión como "Modificación o extinción por el juez en caso de cambio de circunstancias".

\section{Problemas Que Plantea la aPLiCACión de la Cláusula REBUS SIC STANTIBUS Y POSIBLES SOLUCIONES}

1. Según algunos autores, cumplidos los presupuestos de la cláusula rebus sic stantibus, el tribunal deberá modificar o adaptar el contrato, a fin de armonizar lo convenido por las partes, con las nuevas condiciones fácticas que se están desarrollando. La jurisprudencia ha reconocido que, frente a una alteración sustancial de la obligación, el tribunal está autorizado para proceder a modificar el vínculo obligacional ${ }^{50}$. En España,

48 Dicha teoría se puede extraer especialmente de los términos implícitos a los que se refiere la última disposición. En virtud de ella, según SchUlze, Reiner - ZIMmermann, Reinhard, Textos Básicos de Derecho Privado Europeo (Madrid, Marcial Pons, 2002), p. 474 "[j]unto a cláusulas expresas, un contrato puede contener cláusulas implícitas que derivan de: c) Y la buena fe”. A su vez, como destaca Peñailillo ARÉVALO, cit. (n. 33), p. 173, a pesar que es frecuente que la doctrina aluda al artículo 22 del Proyecto franco-italiano como un texto que consagra la teoría de la imprevisión, ello es discutible. Así, de lo señalado por los proyectistas de dicho cuerpo jurídico, se puede concluir que el referido artículo sólo busca consagrar una acción general de rescisión por lesión y contra la usura.

${ }^{49}$ Esta regla se refiere a la imprevisión como cambio de circunstancias: http:// www.jus.uio.no/lm/eu.contract.principles.parts.1.to.3.2002/6.111.html

50 STS de 20 de febrero de 2001, (RJ/2001/1490). En este mismo sentido, la $S T S$ de 20 de noviembre de 2009, procede a decretar la modificación del contrato y no la extinción del contrato con motivo de la cláusula rebus sic stantibus, disponiendo lo siguiente: "La doctrina y la jurisprudencia han aceptado la posibilidad de revisión de un contrato con aplicación del principio general de la cláusula rebus sic stantibus que exige los requisitos de alteración de las circunstancias entre el momento de la perfección del contrato y el de consumación, desproporción exorbitante entre las prestaciones de las partes, lo que ha de haberse producido por un riesgo imprevisible y, por último, la subsidiaridad por no caber otro remedio. Lo cual puede dar lugar no a la extinción del contrato sino a su modificación y revisión. Así lo ha mantenido reiterada jurisprudencia, desde las sentencias de 14 de diciembre de 1940, (RJ/1940/1135), 17 de mayo de 1941, (RJ/1941/632), 17 de mayo de 1957 (RJ/1957/2164) recogidas, entre otras muchas posteriores, por la de 17 de noviembre de 2000, (RJ/2000/9343) y la de 1 de marzo de 2007, (RJ/2007/1618)". STS de 20 de noviembre de 2009, (RJ/2009/7296). En este mismo sentido, conviene mencionar lo dispuesto en la SAP DE NAVARRA, de 18 de octubre de 2010, que procede a establecer otra solución más acorde con el espíritu del contrato, dispone esta sentencia que: "[...] B.- Inaplicación de la cláusula rebus sic stantibus, alegada 
han seguido este criterio, las SSTS de 13 de junio de 1944 (RJ/1944/893 bis); 11 de junio de 1951 (RJ/1951/1649); 23 de noviembre de 1962, (RJ/1962/5005); 28 de enero de 1970, (RJ/1970/503); 6 de noviembre de 1992, (RJ/1992/9226); 4 de octubre de 1996, (RJ/1996/7032) y 20 de febrero de 2001. (RJ/2001/1490) ${ }^{51}$. Esta solución ecléctica, está más acorde con el principio de la conservación del contrato, resultando menos infesta para las pretensiones de los contratantes ${ }^{52}$.

2. Algunos códigos le otorgan acción resolutoria a la parte afectada, es el caso, por ejemplo, del Código civil argentino, (ex artículo 1198). Así, cuando en el contrato se han frustrado las legítimas expectativas o intereses de los contratantes, el contrato ha quedado frustrado y por ello, se debe declarar su resolución ${ }^{53}$.

3. Algunos códigos civiles, como por ejemplo, el de Portugal, el peruano de 1984 y el argentino del 2015, otorgan a la parte perjudicada la posibilidad de solicitar la modificación del contrato o la resolución del mismo ${ }^{54}$.

en el recurso. La doctrina y la jurisprudencia han aceptado la posibilidad de revisión de un contrato con aplicación del principio general de la cláusula rebus sic stantibus que exige los requisitos de alteración de las circunstancias entre el momento de la perfección del contrato y el de consumación, desproporción exorbitante entre las prestaciones de las partes, lo que ha de haberse producido por un riesgo imprevisible y, por último, la subsidiaridad por no caber otro remedio. Lo cual puede dar lugar no a la extinción del contrato sino a su modificación y revisión. Así lo ha mantenido reiterada jurisprudencia, desde las sentencias de 14 de diciembre de 1940, 17 de mayo de 1941, 17 de mayo de 1957 recogidas, entre otras muchas posteriores, por la de 17 de noviembre de 2000 y la de 1 de marzo de 2007. En el presente caso, no puede aplicarse la citada cláusula, pues ni se ha alegado, ni se ha pedido una modificación del contrato, sino la devolución de aquella cantidad”. Tal es la solución que plantea, por ejemplo, el Código Civil EgipCio, el cual en su artículo 147 dispone que: "...el juez puede ajustar en la medida de lo posible, la obligación que se volvió excesiva". Vid. OrSINI, cit. (n. 24), p. 187.

${ }^{51}$ García Caracuel, cit. (n. 20), p. 345.

52 García Caracuel, cit. (n. 20), p. 346.

53 García Caracuel, cit. (n. 20), p. 345.

${ }^{54}$ El artículo 437 del Código Civil Portugués, refiriéndose a las condiciones de admisibilidad de la acción resolutoria, dispone que: "1. Se as circunstâncias em que as partes fundaram a decisão de contratar tiverem sofrido uma alteração anormal, tem a parte lesada direito à resolução do contrato, ou à modificação dele segundo juízos de equidade, desde que a exigência das obrigaçôes por ela assumidas afecte gravemente os princípios da boa fé e não esteja coberta pelos riscos próprios do contrato. 2. Requerida a resolução, a parte contrária pode opor-se ao pedido, declarando aceitar a modificação do contrato nos termos do numero anterior". Norma semejante consagra el CóDigo Civil Peruano, el cual en su artículo 1440 dispone: "En los contratos conmutativos de ejecución continuada, periódica o diferida, si la prestación llega a ser excesivamente onerosa por acontecimientos extraordinarios e imprevisibles, la parte perjudicada puede 
En este sentido, también se ha pronunciado la jurisprudencia española ${ }^{55}$.

4. Por último, pensamos que las partes de un contrato, podrían soslayar la dificultad que implica el hecho de que la cláusula rebus sic stantibus no se encuentre expresamente regulada por la ley, mediante el ejercicio de la autonomía de la voluntad ${ }^{56}$, incorporando cláusulas en sus contratos que estipulen que frente a cambios sociales y económicos. Ese contrato podrá ser revisado por un tribunal, a fin de armonizar las estipulaciones de dicho acuerdo con las nuevas circunstancias fácticas ${ }^{57}$, A nivel mundial, se han incorporado cláusulas en las siguientes especies de contratos: a) En los contratos de suministro de petróleo, se puede acordar que si el gobierno productor de crudo impone un menor precio o gravamen, los contratos vigentes serán revisados. b) En el caso de contratos de desarrollo tecnológico, se puede estipular que si el desarrollo tecnológico tiene un avance tal que deja fuera de competencia a determinados productos, caso en el cual se podrá pedir la modificación de dicho contrato. c) Cuando el gobierno de un país, impone gravámenes a las especies sobre las que recae el o los contratos, serán las partes las que decidan como soportar este tributo o impuesto (a estas estipulaciones se les denomina cláusulas hardship) $)^{58}$.

\section{Algunas notas sobre la Propuesta Española de Modernización del Derecho de Obligaciones y Contratos, de la Comisión General de Codificación, Sección Derecho Civil en torno a la cláusula REBUS SIC STANTIBUS}

En el año 2009, la Comisión General de Codificación, Sección Derecho Civil emitió una Propuesta de Anteproyecto de Ley de Modernización del Derecho de Obligaciones y Contratos, la que, en su Capítulo VIII, titulado

solicitar al juez que la reduzca o que aumente la contraprestación, a fin de que cese la excesiva onerosidad. Si ello no fuera posible por la naturaleza de la prestación por las circunstancias o si lo solicitara el demandado, el juez decidirá la resolución del contrato. La resolución no se extiende a las prestaciones ejecutadas".

55 SAP DE ZaRAGOZA de 21 de febrero de 2001, (JUR/2001/117733).

56 Sánchez Calero, Francisco Javier; Moreno Quesada, Bernardo; Ossorio Morales, Juan; González Porras, José Manuel; Ossorio Serrano, Juan Miguel; Ruiz-Rico Ruiz-Morón, Julia; González García, José; Herrera Campos, Ramón; Orti Vallejo, Antonio y Moreno Quesada, Luis, Curso de Derecho Civil (5a edición, Valencia, Editorial Tirant lo Blanch, 2008), II. Derecho de obligaciones, contratos y responsabilidad por hechos ilicitos, pp. 202 y 203.

57 Díez-Picazo de León y Ponce de León, Luis - Gullón Ballesteros, Antonio, Sistema de Derecho Civil (6a edición, Madrid, Tecnos S. A., 1992), II, p. 273.

${ }^{58} \mathrm{Al}$ respecto, SÁnCHEZ Lorenzo, cit. (n. 10), pp. 1273 y ss. 
"De la alteración extraordinaria de las circunstancias básicas del contrato", aborda por primera vez con carácter general, a la cláusula rebus sic stanti$b u s^{59}$. En efecto, el artículo 1213 de la Propuesta reza: "Si las circunstancias que sirvieron de base al contrato hubieren cambiado de forma extraordinaria e imprevisible durante su ejecución de manera que ésta se haya hecho excesivamente onerosa para una de las partes o se haya frustrado el fin del contrato, el contratante al que, atendidas las circunstancias del caso y especialmente la distribución contractual o legal de riesgos, no le sea razonablemente exigible que permanezca sujeto al contrato, podrá pretender su revisión, y si ésta no es posible o no puede imponerse a una de las partes, podrá aquél pedir su resolución. La pretensión de resolución sólo podrá ser estimada cuando no quepa obtener de la propuesta o propuestas de revisión ofrecidas por cada una de las partes una solución que restaure la reciprocidad de intereses del contrato"60. Con relación a este artículo 1213 de la Propuesta, nos parece razonable efectuar los siguientes comentarios:

a) La Propuesta, en su artículo 1213 se refiere a los requisitos o elementos que hacen procedente la acción de revisión de un contrato, señalando -entre otras exigencias- que las circunstancias que sirvieron de base al contrato hubieren cambiado de forma extraordinaria. Igual adjetivo emplea el epígrafe del Capítulo VIII. Este elemento es similar al que estableciera en el Código civil argentino, el cual, en su ex artículo 1198 , inciso $2^{\circ}$, dispone que: "En los contratos bilaterales conmutativos y en los unilaterales onerosos y conmutativos de ejecución diferida o continuada, si la prestación a cargo de una de las partes se tornara excesivamente onerosa, por acontecimientos extraordinarios e imprevisibles, la parte perjudicada podrá demandar la resolución del contrato. El mismo principio se aplicará a los contratos aleatorios cuando la excesiva onerosidad se produzca por causas extrañas al riesgo propio del contrato" ${ }^{11}$; pero se parece aún más al nuevo artículo 1091 del Código Civil y Comercial argentino (promulgado el 2014

$59 \mathrm{Al}$ respecto puede verse: La teoría de la imprevisión en el Derecho Privado, en Anales de la Facultad de Ciencias Jurídicas y Sociales de la Universidad de La Plata (1961), pp. 2 y ss.

${ }^{60}$ Comisión General de Codificación Sección de Derecho Civil, Propuesta de Anteproyecto de Ley de Modernización del Derecho de Obligaciones y Contratos (Madrid, Editorial Secretaría General Técnica, Centro de Publicaciones, 2009), p. 37.

${ }^{61}$ El carácter extraordinario de la cláusula rebus sic stantibus ha sido reiterado por la jurisprudencia, en numerosas sentencias, por ejemplo: STS de $1^{\circ}$ de octubre de 2008 (RJ/2008/4601); SAP DE VALENCIA de 6 de noviembre de 2000 (JUR/2001/47223); SAP DE BADAJOZ de 10 de junio de 2002 (JUR/2002/201574); SAP DE CÁdiz de 18 de junio de 2004 (JUR/2004/258243); SAP DE CANTABRIA de 18 de mayo de 2006 (JUR/2006/177729); SAP DE BARCELONA de 25 de mayo de $2006(J U R / 2006 / 259574)$. 
y vigente del 2015). Esta norma establece: "Imprevisión. Si en un contrato conmutativo de ejecución diferida o permanente, la prestación a cargo de una de las partes se torna excesivamente onerosa, por una alteración extraordinaria de las circunstancias existentes al tiempo de su celebración, sobrevenida por causas ajenas a las partes y al riesgo asumido por la que es afectada, ésta tiene derecho a plantear extrajudicialmente, o pedir ante un juez, por acción o como excepción, la resolución total o parcial del contrato, o su adecuación. Igual regla se aplica al tercero a quien le han sido conferidos derechos, o asignadas obligaciones, resultantes del contrato; y al contrato aleatorio si la prestación se torna excesivamente onerosa por causas extrañas a su alea propia" ${ }^{2}$. Esta nueva regulación argentina es destacable desde que se mejora la regulación de sus efectos, extendiéndolos a la modificación del contrato por parte del juez, ampliando la legitimación activa y permite que opere como acción o como excepción. El Código civil italiano de 1942 fue absolutamente esencial en la regulación que se hizo en el ex artículo 1198 del CC argentino, que la contempla en su artículo 1467 , titulado "Contratto con prestazioni corrispettive" ${ }^{3}$. Con relación a este requisito, la doctrina y jurisprudencia exigen que el hecho sea imprevisible y extraordinario. Estos conceptos, usualmente, tienden a confundirse. La diferencia radica en que el primero presenta una cierta dimensión subjetiva, ya que indaga en la facultad previsora de cada persona; en cambio, el carácter extraordinario se determina con un criterio objetivo ${ }^{64}$. Esta cuestión será tratada más adelante, cuando se analicen los presupuestos de aplicación de la cláusula rebus sic stantibus ${ }^{65}$.

b) La influencia del $\$ 313$ del $B G B$, también es destacable, en lo que se refiere a la distribución de los riesgos contractuales y legales, el derecho a la adaptación del contrato, y la referencia a la razonabilidad como criterio determinante del derecho a la resolución de la parte perjudicada por la imprevisión.

c) La solución contenida en la Propuesta parece adecuada, por cuanto, la resolución es un derecho subsidiario. El derecho principal es a la revisión del contrato, y sólo en caso que éste no sea posible o no puede imponerse a la parte perjudicada el contrato, en los términos acordados, podrá solicitarse la resolución del mismo ${ }^{66}$. La Propuesta se inclina por el

$62 \mathrm{https} / /$ dpicuantico.com/sitio/wp-content/uploads/2015/06/Civil-Doctrina-2015-06-15.pdf

${ }^{63}$ http://www.jus.unitn.it/cardozo/obiter_dictum/codciv/Lib4.htm/

${ }^{64}$ Para Berrocal Lanzarot, cit. (n. 23), p. 225: "Mientras lo extraordinario es de índole objetiva, resulta discutible la objetividad o subjetividad de la imprevisibilidad".

${ }^{65}$ De AmunÁtegui Rodríguez, cit. (n. 11), p. 259.

${ }^{66}$ En este sentido, De Amunátegui Rodríguez, cit. (n. 11), pp. 317-318. La 
mantenimiento del negocio jurídico y, sólo a falta de tal solución, el juez proceda a la resolución del mismo ${ }^{67}$. Por otra parte, es curioso que para determinar los efectos de la cláusula rebus sic stantibus, la STS de $1^{\circ}$ de junio de 2010 (RJ/2010/2661), haya distinguido entre el momento de la celebración (imposibilidad originaria), lo que se traduce en la nulidad del contrato; y el instante de la ejecución del negocio (imposibilidad sobrevenida), que supone la resolución del contrato. A pesar que dicha sentencia no está de acuerdo con los modernos postulados acerca de los efectos que genera la cláusula rebus sic stantibus, somos de la opinión que es sumamente destacable la mirada que presenta respecto del negocio jurídico ${ }^{68}$. No sólo analiza el momento mismo en que se perfeccionó el contrato, sino que distingue dicho instante del momento preciso en que las obligaciones deben ejecutarse. Lo anterior supone que, en dicho intervalo, no sólo los hechos pueden variar, sino que incluso desaparecer las nociones de causa; equilibrio conmutativo, entre otros ${ }^{69}$.

d) El citado artículo 1213 realiza una mixtura entre varias teorías que pretenden explicar la naturaleza jurídica de la cláusula rebus sic stantibus, ello se denota al emplear la frase: "Si las circunstancias que sirvieron de $b$ a se a lco ntra to..."; y la frase "...o se haya frustrad o elfindel co n trato...". Con relación a este punto, la doctrina ha señalado que la primera parte de esta norma se fundaría en la doctrina de la base del negocio, creada por los juristas alemanes, pues claramente la menciona. Entendemos dicha posición como correcta, por cuanto la doctrina y jurisprudencia española, más que verse influenciadas por el Derecho francés y la teoría de la imprevisión, se han visto fuertemente influidas por la teoría alemana del negocio jurídico y la teoría de la revisión judicial del contrato. Es más los casos de imprevisión se les adscribe más a la revisión judicial del contrato que a la teoría de la imprevisión. Sin perjuicio de lo anterior,

misma autora señala (p. 320 s.) que, tanto en los Principios Unidroit, como en los Principios del Derecho Europeo de Contratos: “...se observa una clara tendencia, [...] favorable al reconocimiento del principio de conservación del contrato”.

${ }^{67}$ En este sentido, se pronuncia Bello Janeiro, Domingo, Comentario a la STS de 6 de noviembre de 1992, en Cuadernos Civitas de Jurisprudencia Civil 30 (1992), p. 1021.

${ }^{68}$ Con respecto a la imposibilidad en el cumplimiento de una obligación, vid. Puig Brutau, José, Fundamentos de Derecho civil (4a edición, Barcelona, Bosch, 1988), I, vol. II, pp. 355 y ss.

${ }^{69}$ STS de $1^{\text {o }}$ de junio de 2010 (RJ/2010/2661). La clasificación de la nulidad en originaria y derivada ha generado ríos de tinta en España. En la práctica, casi ninguno de los grandes civilistas españoles no se ha ocupado de este tema. Para una adecuada síntesis vid. Jerez Delgado, Carmen, La anulación del contrato (Navarra, Civitas y Thomson Reuters, 2011), pp. 20 a 22. 
encontramos una fuerte influencia francesa en el Proyecto de Reforma. Ello es evidente desde que no se recurre a las formas de imposibilidad, que es la técnica ocupada por la revisión judicial del contrato, sino a una regla general de imprevisión ${ }^{70}$. La segunda parte de la norma, en cambio, recibe una clara influencia de los países del common law al referirse a la frustración del fin del contrato (frustation of purpose doctrine). La frustración del fin del contrato, dada la dificultad de diferenciarla de otras situaciones -como los casos de impossibility o de commercial impracticability- exigiría un mejor desarrollo dado que existe una jurisprudencia -que no se ha desarrollado en el presente trabajo-, pero que sería conveniente desarrollarla en la regulación de esta figura. En principio, aunque como se analizó existen autores que estiman en que la excesiva onerosidad en el cumplimiento por parte del deudor es un supuesto de frustración, podría señalarse que una interpretación exegética consideraría la frustración del contrato como es un supuesto específico por el cual el contrato ya no cumple el objeto por el cual se ha convenido entre las partes, y por ende es un supuesto más de resolución que de revisión judicial del contrato. Así, por ejemplo un caso de frustración del contrato es aquel por el cual un ciego que contrata clases para su perro guía, recupera inesperadamente la vista, en cuyo caso: ¡el ex ciego debe pagar las clases del perro que ya no le son necesarias? En estos supuestos la resolución se presenta como una solución general, que podría llevar aparejada una indemnización a favor del acreedor.

e) Es extraño que la Propuesta no establezca un plazo para ejercitar las acciones a que se refiere el artículo 1213 . Por ello, habría que concluir que se debe aplicar el plazo general de prescripción extintiva, contenido en el artículo 1964 del Código civil español, que dispone: "La acción hipotecaria prescribe a los veinte años, y las personales que no tengan señalado término especial de prescripción a los quince." Pensamos que el lapso en cuestión es demasiado extenso, toda vez que lo que se pretende privilegiar es la sub-

${ }^{70}$ En este sentido, la STS de $1^{\circ}$ de marzo de 2007, dispone que: "[...] No estamos ante un supuesto de aplicación de la doctrina de la llamada cláusula rebus sic stantibus, nacida para resolver los problemas derivados de la alteración del equilibrio de las prestaciones contractualmente establecido como consecuencia de alteración sobrevenida fortuita de las circunstancias contempladas al establecer la relación. La posibilidad de aplicar esta llamada "cláusula», que aparece como técnica para enmendar el desequilibrio de las prestaciones a lo largo del tiempo en que deban cumplirse, bajo la indicada forma o bajo fórmulas doctrinales más evolucionadas, como son la teoría de la presuposición, la excesiva onerosidad sobrevenida o la «base del negocio [...]”. STS de 1 de marzo de 2007, (RJ/2007/1618). Al respecto, vid. también RiveRa Restrepo, José Maximiliano, De la causa en el Derecho comparado, en Revista del Magister y Doctorado en Derecho 3 (2011), pp. 293-335, pp. 295-337. 
sistencia del negocio jurídico. Habría sido conveniente que la Propuesta estableciera un plazo menor.

f) Estimamos que sería conveniente incluir una norma intitulada " $D e$ la revisión judicial de los contratos", que englobara no sólo a la cláusula rebus sic stantibus, sino que también a la lesión enorme, no sólo por cuanto constituyen figuras similares, sino que además presentan similares fundamentos.

g) Parece ser adecuado establecer la cláusula rebus sic stantibus en el Libro IV del Código civil, cuyo epígrafe es "De las obligaciones y contratos", pues, en principio, éste sería el ámbito natural en que se desenvuelve aquélla.

b) En este punto, conviene reiterar lo establecido en el Fuero Nuevo de Navarra, de 1973, el que dispone en su Ley $493^{71}$ párrafo tercero que: "Cuando se trate de obligaciones de largo plazo o tracto sucesivo, y durante el tiempo de cumplimiento se altere fundamental y gravemente el contenido económico de la obligación o la proporcionalidad entre las prestaciones, por haber sobrevenido circunstancias imprevistas que hagan extraordinariamente oneroso el cumplimiento para una de las partes, podrá ésta solicitar la revisión judicial para que se modifique la obligación en términos de equidad o se declare su resolución" 72 . La citada Ley del Fuero Nuevo de Navarra de 1973 contiene, según nuestro punto de vista, una interesantísima regulación, por cuanto, en primer lugar, habla de obligaciones a plazo o de tracto sucesivo, es decir, acota de buena manera el ámbito de aplicación de la cláusula rebus sic stantibus, dejando fuera a las obligaciones que nacen de un contrato de ejecución instantánea. Asimismo, es interesante que incluya en su redacción el concepto de equidad, aun cuando lo utilice como criterio para que el juez proceda a revisar los términos del contrato. Con todo, a diferencia de la Propuesta, se refiere a circunstancias imprevistas, cuestión que, como se ha dicho, está errada, por cuanto es preferible hablar de circunstancias imprevisibles por las partes al tiempo de contratar. En cuanto al efecto de la cláusula rebus sic stantibus, nos parece más interesante lo que establece la Propuesta, por cuanto no le otorga el derecho opcional a la parte interesada,

${ }^{71}$ Comentando esta ley, señala que en la tradición del Derecho navarro, puede encontrarse un precedente de la cláusula rebus, toda vez que respondía a una tradición agraria. Si se permutaba un animal por trigo, y el agricultor no podía entregar el trigo a que se había obligado, por mala cosecha, entonces el contrato se resolvía y debía devolver el animal, pagando una indemnización por su utilización, quedando así liberado de su obligación. Aunque esta situación más bien respondía a la idea de caso fortuito o fuerza mayor. Vid. D'Ors PéreZ-PeIX, Álvaro, Tomo XXXVIII. Vol. $2^{\circ}$. Leyes 488 a 596 y Disposiciones transitorias, adicional y final de la Compilación de Navarra, ahora en Salinas Quijada, Francisco - Nanclares, Javier - PardiÑas Sanz, José Ramón - D’Ors Pérez-PeIX, Álvaro (autores), Comentarios al Código Civil (Madrid, Edersa, 2005), disponible en: www.vlex.com

72 Vid. http://www1.unavarra.es/digitalAssets/150/150326_fuero_nuevo.pdf 
sino que le otorga la facultad al tribunal, para que sea éste quien decida si procede la revisión del contrato o su resolución. Lo anterior, está conforme a lo que plantea la doctrina moderna en esta materia, en el sentido de que debe estarse primero por el mantenimiento del contrato (revisión de sus cláusulas), y sólo cuando ello no fuere posible o no pueda imponerse a una de las partes, se debe proceder a resolver el contrato.

i) La aprobación de la Propuesta, en lo que se refiere al artículo 1213, tendría -en nuestra opinión- un positivo efecto en el Derecho civil, porque implicaría incluir a la legislación, las modernas doctrinas que sobre la materia se han creado, por ejemplo, la noción de hardship contenida en el artículo 6.2.2. de los Principios UNIDROIT ${ }^{73}$. Esta norma establece que: "Hay «excesiva onerosidad" (hardship) cuando el equilibrio del contrato es alterado de modo fundamental por el acontecimiento de ciertos eventos, bien porque el costo de la prestación a cargo de una de las partes se ha incrementado, o porque el valor de la prestación que una parte recibe ha disminuido, y: (a) dichos eventos acontecen o llegan a ser conocidos por la parte en desventaja después de la celebración del contrato; (b) los eventos no pudieron ser razonablemente tenidos en cuenta por la parte en desventaja en el momento de celebrarse el contrato; (c) los eventos escapan al control de la parte en desventaja; $y$ (d) el riesgo de tales eventos no fue asumido por la parte en desventaja" ${ }^{74}$. Esta disposición establece cuando hay excesiva onerosidad ( $h a r d s h i p$ ), es decir, cuando el equilibrio de las prestaciones contractuales es afectado de manera fundamental, siempre que se cumplan las cuatro condiciones establecidas en este artículo. Ahora bien, el principio general es que el cambio en las circunstancias no afecta el deber de cumplir con la prestación (artículo 6.2.1), salvo que la excesiva onerosidad obedezca a una alteración del equilibrio de las prestaciones sea esencial, ésta es una cuestión de hecho determinada caso a caso, por el juez.

Por último, los Principios de Derecho Europeo de los Contratos disponen, en su artículo 6.111, cuyo epígrafe es "Cambio de Circunstancias", que: "(1) Las partes deben cumplir con sus obligaciones, aun cuando les resulten más onerosas como consecuencia de un aumento en los costes de la ejecución o por una disminución del valor de la contraprestación que se recibe. (2) Sin embargo, las partes tienen la obligación de negociar una adaptación de dicho contrato o de poner fin al mismo si el cumplimiento del contrato resulta exce-

73 Salvador Coderch, Pablo, Alteración de circunstancias en el art. 1213 de la Propuesta de Modernización del Código Civil en materia de Obligaciones y Contratos, en Revista para el análisis del Derecho, Facultad de Derecho, Univesitat Pompeu Fabra (2009), p. 8.

${ }^{74}$ Principios UNIDROIT sobre los Contratos Comerciales Internacionales (Roma, Instituto Internacional para la Unificación del Derecho Privado, 2007), p. 190. 
sivamente gravoso debido a un cambio de las circunstancias, siempre que: (a) Dicho cambio de circunstancias haya sobrevenido en un momento posterior a la conclusión del contrato. (b) En términos razonables, en el momento de la conclusión del contrato no hubiera podido preverse ni tenerse en consideración el cambio acaecido. (c) A la parte afectada, en virtud del contrato, no se le pueda exigir que cargue con el riesgo de un cambio tal de circunstancias. (3) Si en un plazo razonable las partes no alcanzan un acuerdo al respecto, el juez o tribunal podrá: (a) Poner fin al contrato en los términos y fecha que considere adecuado. (b) O adaptarlo, de manera que las pérdidas y ganancias resultantes de ese cambio de circunstancias se distribuyan entre las partes de forma equitativa y justa. En cualquiera de los casos, el juez o tribunal podrá ordenar que la parte que se negó a negociar o que rompió dicha negociación de mala fe, proceda a reparar los daños causados a la parte que sufrió dicha negativa o dicha ruptura"75.

\section{Conclusiones Finales}

a) Estimamos que la denominación cláusula rebus sic stantibus es equívoca y poco feliz, ya que la imprevisión no constituye una cláusula del contrato. La denominación correcta es aquella que le otorgó en 1916 el Consejo de Estado francés, a propósito del caso que enfrentó a la Compañía de Gas de Burdeos con la Municipalidad de dicha ciudad, es decir, "teoría de la imprevisión". Dicha expresión parece ser la más adecuada para la Propuesta. Sin perjuicio de lo cual, la expresión "cambio de las circunstancias del contrato", o "revisión judicial del contrato" no pueden dejarse totalmente de lado, a pesar que tampoco están exentas de problemas. En general se puede sostener que la utilización de una u otra expresión dependen del antecedente legislativo que se ocupe, lo cual no está bien resuelto en la Propuesta.

b) Un estatuto que regule a la cláusula rebus sic stantibus, en los términos abordados por la Propuesta, debiese contemplar la experiencia acumulada por la doctrina y jurisprudencia alemana, italiana e incluso la americana. Sin embargo, también hay que tener presente las normas contenidas en varios códigos civiles, tales como el argentino y el holandés. Si bien, el artículo 1213 de la Propuesta de Anteproyecto de Ley de Modernización del Derecho de Obligaciones y Contratos se ajusta al Derecho Civil moderno, optaría por una propuesta más sencilla y clara, tal como la contenida en

${ }^{75}$ Principios de Derecho Europeo de los Contratos, preparadoss por la Comisión de Derecho europeo de los contratos (traducción del texto de los artículos publicados en Lando, Beale, eds., Principles of European Contract Law, La Haya, Kluwer Law International, 2000), I y II, revisadas, pp. 23-24. 
la Ley 493, apartado 3, del Fuero Nuevo de Navarra de 1973. Esta ley hace alusión a la equidad natural, término que, si bien es indeterminado y complejo, le otorga al juez un adecuado marco de libertad y se ajusta de buena forma a la tradición europea continental.

c) En cuanto a los efectos que debería tener esa futura ley, pensamos que es necesario aprobar el contenido de la Propuesta, en cuanto a que sea el juez el que proceda a revisar el contrato y si esta revisión no es posible, proceda a declarar la resolución del contrato. Esta solución cumpliría con el brocardo de la equidad natural y el principio de mantenimiento del contrato. Sin embargo, sería conveniente incluir un artículo más genérico, que se intitulara: "De la revisión judicial del contrato", y que contuviera tanto a la teoría de la cláusula rebus sic stantibus como a la lesión enorme. Como se dijo, la Propuesta, en su artículo 1213 se refiere a los requisitos que hacen procedente la acción de revisión de un contrato, señalando -entre otras exigencias- que las circunstancias que sirvieron de base al contrato hubieren cambiado de forma extraordinaria. Con todo, bastaría con señalar que se trate de un acontecimiento imprevisible, para que el tribunal procediera a aplicar la cláusula rebus sic stantibus. El problema que se atisba en la exigencia contenida en el artículo 1213 de la Propuesta, en orden a emplear el vocablo extraordinario, que generará problemas de interpretación. El citado artículo 1213 realiza una mixtura entre varias teorías que pretenden explicar la naturaleza jurídica de la cláusula rebus sic stantibus. En nuestra opinión, no parece ser conveniente incorporar en el texto de la Propuesta teorías que, siendo similares, no son idénticas. En otras palabras parece acertado el recurrir a lo que se ha denominado como cláusulas generales, que permiten que la jurisprudencia vaya realizando disquisiciones que conducen a mejorar el Derecho; pero dado que se recurre a una pluralidad de fuentes de esta cláusula (la francesa, alemana e inglesa y americana) -y como, dentro de dichas fuentes la dogmática comparada no termina en ponerse de acuerdo en aspectos relevantes- convendría haber especificado un poco más los supuestos de la cláusula rebus sic stantibus.

d) El ámbito de aplicación de la cláusula rebus sic stantibus, en general, se limita a las obligaciones surgidas de contratos de tracto sucesivo o de ejecución diferida. Aun cuando ella puede operar en obligaciones nacidas de otras fuentes. La cláusula rebus sic stantibus no sólo se aplica a los contratos conmutativos, sino también a los aleatorios, cuando del contenido de las cláusulas contractuales (en los términos ya indicados).

e) Es criticable que la Propuesta, no establezca un plazo para ejercitar las acciones a que se refiere el citado artículo. En principio, habría que concluir que se debe aplicar el plazo general de prescripción, contenido en el artículo 1964 del Código Civil. Este lapso aparece como excesivo, pienso 
que un término razonable para intentar la referida acción, debiese fluctuar entre los seis meses y los dos años, constituyendo una prescripción de corto tiempo, ya que, mantener la incertidumbre de la relación jurídica durante quince años atentaría contra la seguridad jurídica y la consolidación de las instituciones de Derecho inciertas.

f) La jurisprudencia ha efectuado una aplicación restringida de la cláusula rebus sic stantibus, estableciendo con gran rigidez los presupuestos de la misma y analizándolos restrictivamente a la hora de interpretarlos (a pesar de las últimas sentencias del TS). Por ello, es imprescindible que el legislador consagre la cláusula rebus sic stantibus en el Código Civil, pero para que esta Reforma tenga éxito es fundamental poder tener un adecuado equilibrio entre discrecionalidad judicial -a través de las clásulas generales- y la necesidad de fijar con precisión el ámbito de aplicación de la referida cláusula.

\section{BibLIOGRAFÍA}

Alterini, Atilio, Teoría de la imprevisión y cláusula de hardship, en Rivista di Diritto dell'Integrazione e Unificazione del Diritto in Europa e in America Latina 13 (2002), pp. 53-69.

Álvarez Caperochipi, José Antonio, Curso de Derecho de obligaciones. El Derecho de los contratos (Madrid, Editorial Civitas, 2002).

Barcia Lehmann, Rodrigo, Breve Análisis de la Teoría de la Imprevisión en el Derecho Chileno, en Tribunal Supremo de Justicia (editor), Libro de Homenaje al Prof. J. L. Aguilar (Colección de Libros Homenaje, N 5, Caracas, 2002), I, pp. 191 - 211.

Barcia Lehmann, Rodrigo, ¿Es Posible Construir la Teoría General del Contrato desde la Excepción: la Revisión Judicial del Contrato?, ahora, en MARTINIC, María Dora Tapia R., M. (directores), Sesquicentenario del Código Civil de Andrés Bello: Pasado, Presente y Futuro de la Codificación (Santiago de Chile, Facultad de Derecho de la Universidad de Chile, LexisNexis, 2005), I, pp. 685 a 719.

Bello JaneIro, Domingo, Comentario a la STS de 6 de noviembre de 1992, en Cuadernos Civitas de Jurisprudencia Civil 30 (1992), pp. 1009-1024.

Berrocal Lanzarot, Ana Isabel, La cláusula rebus sic stantibus. A propósito de la Sentencia del Tribunal Supremo, del Pleno de la Sala Primera, de 17 de enero de 2013, en García Collantes, José Manuel (director), Cuadernos de Derecho y Comercio 60 (Madrid, Consejo General de los Colegios Oficiales de Corredores de Comercio, 2014), pp. 199-246.

BerRocal LANZAROT, Ana Isabel, La reducción de la pensión de alimentos por alteración sustancial de las circunstancias, en Revista Critica de Derecho Inmobiliario 742 (2014), pp. 620-644.

Busto Lago, José Manuel, Sentencia de 8 de noviembre de 2012. Acción de resolución de compraventa inmobiliaria fundada en el incumplimiento del término esencial de la obligación de entrega. La licencia de primera ocupación integra la obligación de entrega. Inaplicación de la regla "rebus sic stantibus», en Cuadernos Civitas de Jurisprudencia Civil 94 (2014), pp. 53-70. 
Caramelo, Gustavo, Título II, Capitulo 13 - Extinción, modificación y adecuación del contrato, ahora en Herrera, Marisa - Caramelo, Gustavo - Picasso, Sebastián (directores), Álvarez, J. (dirección editorial), Código Civil y Comercial de la Nación Comentado, Libro Tercero, artículos 724 a 1250. Disponible en http:// www.infojus.gob.ar/docs-f/codigo-comentado/CCyC TOMO 3 FINAL completo digital.pdf

CastiñeIra Jerez, Jorge, Pacta sunt servanda, imprevisión contractual y alteración sobrevenida de las circunstancias, en Revista Aranzadi de Derecho Patrimonial 29 (2012), pp. 71-106.

Castro Conte, Macarena, El sistema normativo del salario: ley, convenio colectivo, contrato de trabajo y poder del empresario (Madrid, Dykinson, 2007).

Comisión General de Codificación Sección de Derecho Civil, Propuesta de Anteproyecto de Ley de Modernización del Derecho de Obligaciones y Contratos (Madrid, Editorial Secretaría General Técnica, Centro de Publicaciones, 2009).

CHAmiE, José Félix, Frustration of Contract e Impossibility of performance en el Common Law estadounidense, en: Revista de Derecho Privado, 18 (2010), pp. 95-122.

De Amunátegui Rodríguez, Cristina, La cláusula rebus sic stantibus (Valencia, Editorial Tirant lo Blanch, 2003).

De Castro y Bravo, Federico, El Negocio Jurídico (Civitas, Madrid, 1991).

De Cuevillas Matozzi, Ignacio - De Castro García, Jaime - González GarcíaMier, Rocío, Instituciones de Derecho civil patrimonial (Cuarta Edición, Madrid, Editorial Tecnos, 2011).

De la Iglesia Prados, Eduardo, Consecuencias contractuales derivadas del incumplimiento urbanistico, ahora en Morillas Cueva, Lorenzo (director), SuÁrez López, José María (coordinador), Urbanismo y corrupción política. (Una visión penal, civil y administrativa) (Madrid, Dykinson, S. L., 2013), pp. 635-690.

Díez-Picazo y Ponce de León, Luis, Fundamentos de Derecho Civil patrimonial (Madrid, Editorial Civitas, 1996), II.

Díez-Picazo de León y Ponce de León, Luis - Gullón Ballesteros, Antonio, Sistema de Derecho Civil (6a edición, Madrid, Tecnos S. A., 1992), II.

D'Ors PéreZ-PeIX, Álvaro, Tomo XXXVIII. Vol. 2. Leyes 488 a 596 y Disposiciones transitorias, adicional y final de la Compilación de Navarra, ahora en SALINAS Quijada, Francisco - Nanclares, Javier - Pardiñas Sanz, José Ramón - D’OrS Pérez-Peix, Álvaro (autores), Comentarios al Código Civil (Madrid, Edersa, 2005), disponible en: www.vlex.com

EISENBERG, Melvin, Impossibility, Impractiability, and Frustration, en: Berkeley Law Scholarship Repository, (2009), pp. 207-266.

Farnsworth, Allan, Contracts ( $3^{\text {a }}$ edición, Aspen, Aspen Law \& Business - Aspen Publishers, Inc., 1999).

FERnANDES DE AlmeIDA, Roberto, Alteración de las circunstancias y revisión contractual (Tesis Doctoral, Universidad de Salamanca, Salamanca, 2011).

Flour, Jacques - Aubert, Jean-Luc - Savaux, Éric, Droit Civil. Les obligations (París, Éditorial Dalloz, 2004), 1.

GARCíA CARACUEL, Manuel, La alteración sobrevenida de las circunstancias contractuales (Madrid, Dykinson, 2014).

Ghestin, Jacques, Traité de Droit Civil: Les Obligations. Les Effets du Contract (Paris, Librairie Générale de Droit et Jurisprudence, 1992). 
IZQUierdo TOlSADA, Mariano, La cláusula rebus sic stantibus no puede dar tanto de sí, en Boletín Mercantil 18, (2014), www.vlex.com.

Jerez Delgado, Carmen, La anulación del contrato (Navarra, Civitas y Thomson Reuters, 2011).

JimÉNEZ MuÑoz, Francisco Javier, La moderación judicial de la cláusula penal, en Revista Critica de Derecho Inmobiliario 653 (1999), pp. 1455-1494.

Kessler, Friedrich - Gilmore, Grant and Kronman, Anthony, Contracts. Cases and Materials ( $3^{a}$ edición, Aspen, Aspen law \& Business - Aspen Publishers, Inc., 1987).

Kötz, Hein y Zweigert, Konrad, Introduction to Comparative Law (New York, Editorial Oxford University Press, 1998).

Lacruz Berdejo, José Luis - Sancho Rebullida, Francisco - Luna Serrano, Agustín; Delgado Echeverría, Jesús; Rivero Hernández, Francisco - Rams Albesa, Joaquín, Elementos de Derecho Civil (5a edición revisada y puesta al día por F. Rivero Hernández, Madrid, Dykinson, 2011), II.

Lacruz Berdejo, José Luis - Sancho Rebullida, Francisco - Luna Serrano, Agustín; Delgado Echeverría, Jesús; Rivero Hernández, Francisco - Rams Albesa, Joaquín, Elementos de Derecho Civil ( $4^{a}$ edición revisada y puesta al día por F. Rivero Hernández, Editorial Dykinson, Madrid, 2007), II, vol. 1.

Larenz, Karl, Base del Negocio Jurídico y Cumplimiento de los Contratos (Madrid, Editorial Revista de Derecho Privado, 1956).

LeONSEgui Guillot, Rosa Adela, El contrato de opción como contrato atípico de tracto único: examen jurisprudencial de la aplicabilidad de la resolución por cambio o alteración de las circunstancias, en Revista de Derecho UNED 10 (2012), pp. 315-345.

López Monroy, José de Jesús, La cláusula rebus sic stantibus o teoría de la imprevisión, en Patiño Manffer, Ruperto, Cultura Jurídica. De los Seminarios de la Facultad de Derecho 3 (2011), pp. 73-81.

Luna Yerga, Álvaro - XIOL Bardají, María, Rebus sic stantibus: ¿Un paso atrás? Comentario a la STS, 1a, 15.10.2014 (Ar. 6129) y a la jurisprudencia posterior de la Sala Primera del Tribunal Supremo sobre la regla rebus sic stantibus, en InDret. Revista para el Análisis del Derecho 2 (2015), pp. 1-13.

Marín Narros, Héctor Daniel, La aplicación de la cláusula rebus sic stantibus en los contratos bancarios y su interpretación por la STS de 29 de octubre de 2013 y la jurisprudencia menor, en Revista Crítica de Derecho Inmobiliario 747 (2015), pp. 532-559.

MarTínez Atienza, Gorgonio, Jurisprudencia civil, en Derecho civil, penal sustantivo y procesal. Jurisprudencia del Tribunal Supremo (2015), pp. 324-365.

Martínez Velencoso, Luz, Riesgo negocial versus "cláusula rebus sic statibus». Comentario a las SSTS, 1a, 1.6.2010 y 21.7.2010, en InDret. Revista para el Análisis del Derecho 10, Barcelona (2011), pp. 1-17.

MELICH ORSINI, José, La revisión judicial del contrato por onerosidad excesiva, en Revista de Derecho de la Universidad Católica de Valparaiso XX (1999), pp. 163-194.

Moisset de EspaÑés Luis, La lesión en el nuevo artículo 954 del Código Civil argentino y en algunas legislaciones modernas, en Anuario de Derecho Civil 29 (1976), pp. $85-1552$.

Momberg Uribe, Rodrigo, Teoría de la imprevisión: la necesidad de su regulación legal en Chile, en Revista Chilena de Derecho 15 (2010), pp. 29-64.

Murphy, Edward - Speidel, Richard - Ayres, Ian, Studies in Contract Law (Westbury, University Casebooks Series, New York, The Foundation Press, Inc., 1997). 
Palacios Ramírez, Jaime, La incidencia de la crisis económica en la doctrina general de los contratos (Logroño, Servicio de Publicaciones, Universidad de La Rioja, 2014).

Parada Guzmán, César, Fundamentos de la Teoría de la Imprevisión (Santiago de Chile, Colegio de Abogados de Chile, 1994).

Peñailillo Arévalo, Daniel, La revisión judicial de obligaciones y contratos, en Revista de Derecho, Universidad de Concepción LXVIII (2000).

Principios de Derecho Europeo de los Contratos, Preparadas por la Comisión de Derecho europeo de los contratos (traducción del texto de los artículos publicados en Lando, Beale, eds., Principles of European Contract Law, La Haya, Kluwer Law International, 2000), I y II, revisadas.

PRINCIPIOS UNIDROIT SOBRE LOS CONTRATOS COMERCIALES INTERNACIONALES 2010a, disponible en http://www.unidroit.org/

Principios UNIDROIT Sobre los Contratos Comerciales Internacionales (Roma, Instituto Internacional para la Unificación del Derecho Privado, 2007).

Puig Brutau, José, Fundamentos de Derecho civil (Cuarta edición, Barcelona, Bosch, 1988), I, vol. II.

Rivera Restrepo, José Maximiliano, De la causa en el Derecho comparado, en Revista del Magister y Doctorado en Derecho 3 (2011), pp. 293-335.

Salas Carceller, Antonio, La causa en los contratos y la llamada ruptura de la base del negocio, en Revista Aranzadi Doctrinal 6/2010 (2010). Disponible en http:// www.westlaw.com

Salvador Coderch, Pablo, Alteración de circunstancias en el art. 1213 de la Propuesta de Modernización del Código Civil en materia de Obligaciones y Contratos, en Revista para el análisis del Derecho, Facultad de Derecho, Univesitat Pompeu Fabra (2009).

Sánchez Calero, Francisco Javier; Moreno Quesada, Bernardo; Ossorio Morales, Juan; González Porras, José Manuel; Ossorio Serrano, Juan Miguel; Ruiz-Rico Ruiz-Morón, Julia; González García, José; Herrera Campos, Ramón; Orti Vallejo, Antonio y Moreno Quesada, Luis, Curso de Derecho Civil (5 $5^{\mathrm{a}}$ edición, Valencia, Editorial Tirant lo Blanch, 2008), II. Derecho de obligaciones, contratos y responsabilidad por hechos ilícitos.

SÁnchez Lorenzo, Sixto Hardship en la contratación internacional: Principios comunes para una unificación desde el Derecho comparado, ahora en VARGAS GÓMEZ-URRUTIA, Marina - SAlinAS DE FRíAs, Ana. (coordinadoras), Soberanía del Estado y Derecho internacional (Homenaje al Profesor Juan Antonio Carrillo Salcedo) (Sevilla, Servicios de Publicaciones de las Universidades de Córdoba, Sevilla y Málaga, 2005), pp. 1273-1292.

Sánchez Peí Valle, José, Sugerencias a la doctrina de la cláusula rebus sic stantibus, en Revista Crítica de Derecho Inmobiliario 311 (1954), pp. 262-265.

San Miguel Pradera, Lis Paula, La excesiva onerosidad sobrevenida: una propuesta de regulación europea, en Anuario de Derecho Civil, N LV-3 (2002), pp. 1115-1132.

Schulze, Reiner - Zimmermann, Reinhard, Textos Básicos de Derecho Privado Europeo (Madrid, Marcial Pons, 2002).

Trigo Sierra, Eduardo y Pérez-PujAzón, María Encarnación, El nuevo tratamiento jurisprudencial de la doctrina de la cláusula rebus sic stantibus, en Actualidad Jurídica Uría Menéndez, 39 (2015), pp. 88-94.

Villate, Guillermo, La teoría de la imprevisión en el Derecho Privado, en Anales de la Facultad de Ciencias Jurídicas y Sociales de la Universidad de La Plata (1961). 
Weiskopf, Nicholas, Frustration of Contractual Purpose - Doctrine or Myth?, en: St. John's Law Review, 70 (1996), pp. 239-271.

\section{ÍNDICE DE SENTENCIAS}

Auto de TS de 18 de noviembre de 2015, (RJ/2014/1875).

STS de 24 de febrero de 2015, (RJ/2015/64).

STS de 15 de octubre de 2014, (RJ/2014/591).

STS de 30 de junio de 2014, (RJ/2014/333).

STS de 26 de marzo de 2014, (RJ/2012/86).

STS de $1^{\circ}$ de junio de 2010, (RJ/2010/2661).

STS de 20 de noviembre de 2009, (RJ/2009/7296).

STS de $1^{\circ}$ de octubre de 2008, (RJ/2008/4601).

STS de $1^{\circ}$ de marzo de 2007, (RJ/2007/1618).

STS de 27 de mayo de 2002 (RJ/2002/4573).

STS de 20 de febrero de 2001, (RJ/2001/1490).

STS de 17 de noviembre de 2000, (RJ/2000/9343).

STS de 15 de noviembre de 2000, (RJ/2000/9214).

STS de 4 de octubre de 1996, (RJ/1996/7032).

STS de 20 de abril de 1994 (RJ/1994/3216).

STS de 6 de noviembre de 1992, (RJ/1992/9226).

STS de 9 de mayo de 1983 (RJ/1983/2678).

STS de 14 de febrero de 1976, (RJ/1976/617).

STS de 28 de enero de 1970, (RJ/1970/503).

STS de 23 de noviembre de 1962, (RJ/1962/5005).

STS de 6 de junio de 1959 (RJ/1959/3026).

STS de 17 de mayo de 1957 (RJ/1957/2164).

STS de 11 de junio de 1951, (RJ/1951/1649).

STS de 13 de junio de 1944, (RJ/1944/893 bis).

STS de 17 de mayo de 1941, (RJ/1941/632).

STS de 14 de diciembre de 1940, (RJ/1940/1135).

SAP de A Coruña, de 19 de octubre de 2015, n 371/2015.

SAP de Madrid, de 6 de octubre de 2015, Sección 3a n $^{\circ} 325 / 2015$.

SAP de Badajoz, Sección 3a , de 9 de octubre de 2015, n 223/2015.

SAP de Badajoz, Sección 3 $3^{\text {a }}$, de 7 de octubre de 2015, n 200/2015.

SAP de Las Palmas, Sección 5a , de 30 de septiembre de 2015, nº 407/2015.

SAP de Badajoz, Sección $3^{\text {a }}$, de 7 de octubre de 2015, n 200/2015.

SAP de Albacete, Sección 1a de 29 de septiembre de 2015, nº 221/2015.

SAP de Madrid, Sección 21 a de 29 de septiembre de 2015, n 304/2015.

SAP de la Audiencia Provincial de Córdoba, Sección 1. a , de 14 de marzo de 2013, (JUR/2013/251585).

SAP de la Audiencia Provincial de Cádiz, Sección 2.a , de 10 de enero de 2012, (JUR/2012/77632).

SAP de Navarra, de 18 de octubre de 2010 (JUR/2010/231994).

SAP de Barcelona de 25 de mayo de 2006, (JUR/2006/259574).

SAP de Cantabria de 18 de mayo de 2006, (JUR/2006/177729).

SAP de Cádiz de 18 de junio de 2004, (JUR/2004/258243).

SAP de Navarra de 20 de diciembre de 2002, (AC/2002/329). 
SAP de Badajoz de 10 de junio de 2002, (JUR/2002/201574).

SAP de Barcelona de 16 de mayo de 2002, (JUR/2002/189101).

SAP de la Audiencia Provincial de Asturias, Sección 5.a, de 4 de abril de 2001, (AC/2001/1046).

SAP de Zaragoza de 21 de febrero de 2001, (JUR/2001/117733).

SAP de la Audiencia Provincial de Madrid, Sección 14, de 20 de febrero de 2001, (JUR/2001/184592).

SAP de Valencia de 6 de noviembre de 2000, (JUR/2001/47223).

SAP de A Coruña de 21 de octubre de 1994, (AC/1994/1829). 